\title{
Ash plume top height estimation using AATSR
}

\author{
T. H. Virtanen ${ }^{1}$, P. Kolmonen ${ }^{1}$, E. Rodríguez ${ }^{1}$, L. Sogacheva ${ }^{1}$, A.-M. Sundström ${ }^{2}$, and G. de Leeuw ${ }^{1,2}$ \\ ${ }^{1}$ Finnish Meteorological Institute, Erik Palmenin aukio 1, 00560 Helsinki, Finland \\ ${ }^{2}$ Department of Physics, University of Helsinki, Gustav Hällströmin katu 2a, 00560 Helsinki, Finland
}

Correspondence to: T. H. Virtanen (timo.h.virtanen@fmi.fi)

Received: 17 March 2014 - Published in Atmos. Meas. Tech. Discuss.: 16 April 2014

Revised: 24 June 2014 - Accepted: 1 July 2014 - Published: 8 August 2014

\begin{abstract}
An algorithm is presented for the estimation of volcanic ash plume top height using the stereo view of the Advanced Along Track Scanning Radiometer (AATSR) aboard Envisat. The algorithm is based on matching top of the atmosphere (TOA) reflectances and brightness temperatures of the nadir and $55^{\circ}$ forward views, and using the resulting parallax to obtain the height estimate. Various retrieval parameters are discussed in detail, several quality parameters are introduced, and post-processing methods for screening out unreliable data have been developed. The method is compared to other satellite observations and in situ data. The proposed algorithm is designed to be fully automatic and can be implemented in operational retrieval algorithms. Combined with automated ash detection using the brightness temperature difference between the 11 and $12 \mu \mathrm{m}$ channels, the algorithm allows efficient simultaneous retrieval of the horizontal and vertical dispersion of volcanic ash. A case study on the eruption of the Icelandic volcano Eyjafjallajökull in 2010 is presented.
\end{abstract}

\section{Introduction}

Information on the dispersion of volcanic ash is important for air traffic safety, and satellite observations are the only way to obtain near real-time (NRT) information on volcanic ash plumes on regional and global scales. Specialized satellite data products can be used by the airline industry and aviation authorities to avoid flying in areas affected by ash. In addition, the satellite observations are crucial for constraining ash dispersion models used for ash forecasts. While geostationary satellites with high temporal resolution are best suited to near real-time ash monitoring, the polar-orbiting satellites can often provide more detailed information. In particular, the vertical profile of volcanic ash plumes can be studied using satellite-based multiview instruments. Detailed studies of the plume heights of past eruptions can help to understand the ash dispersion phenomena and to improve the dispersion models.

Height estimates based on multi-angle satellite data using stereo matching techniques have been used for decades. Early work by Hasler (1981) on satellite-based stereo matching height estimates employed two geostationary satellites, and required manual matching of a pair of images. Since then, multiview satellite instruments have become available, and automatic image processing techniques have been developed. Prata and Turner (1997) introduced an algorithm for cloud top height estimates using Along Track Scanning Radiometer (ATSR) data. Their method is based on maximizing the cross-correlation of nadir and forward views by allowing the forward view to be shifted. Muller et al. (2002) developed stereoscopic image matchers for the Multi-angle Imaging SpectroRadiometer (MISR), based on minimizing the difference between views, and Muller et al. (2007) describe a refined method for ATSR-2 data. Fisher et al. (2013) further developed these methods using Advanced Along Track Scanning Radiometer (AATSR) data. The MISR height estimate methods have been applied to volcanic ash plumes, e.g., by Scollo et al. (2012). Recently, Zakšek et al. (2013) proposed a method combining Spinning Enhanced Visible and InfraRed Imager (SEVIRI) and Moderate-resolution Imaging Spectroradiometer (MODIS) data. Ash plume heights have also been studied by Grainger et al. (2013) using AATSR, SEVIRI, and MIPAS (Michelson Interferometer for Passive Atmospheric Sounding) data.

Other methods for plume top height estimate include satellite-based lidars, brightness temperatures (BT) methods, and $\mathrm{CO}_{2}$ absorption techniques. The Cloud-Aerosol Lidar 
with Orthogonal Polarization (CALIOP) has a vertical resolution of up to $30 \mathrm{~m}$, but a very limited coverage. BT methods are based on comparing the measured plume BT to atmospheric temperature profiles, and the absorption technique uses the wavelength dependence of $\mathrm{CO}_{2}$, but these methods generally do not provide the same accuracy as the purely geometric stereo matching methods. These alternative methods have recently been discussed, e.g., by Zakšek et al. (2013) and Ekstrand et al. (2013).

Information on the ash plume height and thickness is also important for aerosol retrieval, in particular in estimating the ash concentrations. The satellite-based instruments typically measure only the total aerosol load in an atmospheric column, without information on the aerosol profile or concentration. Information on the cloud thickness is needed in converting the satellite-retrieved column amounts $\left(\mathrm{g} \mathrm{m}^{-2}\right)$ to concentrations $\left(\mathrm{g} \mathrm{m}^{-3}\right)$. The radiative transfer models often use rough guesses for the height and thickness of the aerosol layers, e.g., a homogeneous layer between 0 and $2 \mathrm{~km}$ might be assumed. This is usually adequate in the retrieval of the ambient aerosol optical depth (AOD) over broad areas with relatively low concentrations. The ash plumes, however, are distinct features, forming a high contrast with the background and having highly varying heights in general. Thus, information on the plume height may be of considerable importance to the ash load retrievals. Information on plume height and thickness that can be directly obtained from the stereo view geometry of AATSR is limited, but nevertheless valuable. Work on combining the AATSR dual view (ADV) aerosol retrieval algorithm (Kolmonen et al., 2013) with the AATSR correlation method (ACM) plume top height algorithm and automated ash detection is in progress. The aim is to simultaneously acquire information on the horizontal plume position and ash mass load, in addition to the plume height. The ash-specific AOD retrieval will be discussed elsewhere.

In this article we describe an elevated-feature height estimation algorithm for AATSR. Although our focus is on volcanic ash plumes, the method can in principle be used to estimate cloud top heights $(\mathrm{CTH})$ or the height of any other feature, such as smoke and dust plumes or surface topography, provided that there is enough contrast in the measured top of atmosphere (TOA) reflectances or brightness temperatures. The ACM algorithm is largely based on existing methods. New aspects are that we allow a simultaneous acrosstrack shift of the forward view, to compensate for acrosstrack wind components. We also introduce and use several quality parameters based on statistical analyses and allow simultaneous use of multiple correlation window sizes in the retrievals. New post-processing techniques to remove unreliable data are discussed as well. One of the key advantages in our approach is the automated ash detection using the brightness temperature difference method. The plume top heights are calculated for ash-flagged pixels only, making the algorithm very efficient in processing large quantities of data.
From the available multiview instruments, AATSR is the optimal choice for ash plume height estimates. AATSR is unique in its ability to both detect volcanic ash using the thermal infrared (TIR) channels and to estimate the plume top height using the stereo view. In this paper we apply the height estimate algorithm to AATSR data only, although it is possible to apply it to MISR as well. Connection to ENVISAT was lost in April 2012, so the method presented here can only be applied to historical cases. The successor of AATSR, the Sea and Land Surface Temperature Radiometer (SLSTR) is scheduled for launch in 2015. It has similar characteristics to AATSR (TIR channels and stereo view), and the method presented here can be applied to SLSTR data.

In Sect. 2, the area-based correlation method algorithm for the estimation of volcanic ash plume top heights is described. In this method the correlation between brightness temperature data for the two views is optimized by shifting the forward-view data in the along-track direction. In Sect. 3 we show comparison to available remote sensing and in situ data as well as against surface height data. In Sect. 4 we apply the method to the 2010 eruption of Eyjafjallajökull as a test case. Conclusions are given in Sect. 5.

\section{Ash plume height estimate}

Here we describe the characteristics of the AATSR instrument (Sect. 2.1), the ash detection technique (Sect. 2.2), the basic ideas behind the stereo view height estimate method (Sect. 2.3), and the ACM height estimate algorithm (Sect. 2.4). The height estimate results depend on several parameters used in the retrieval; these are discussed in Sect. 2.5. The primary product of ACM is the single-pixel height, calculated separately for each ash-flagged pixel. In addition, an averaged (smoothed) height product is provided, where the acceptance of pixels for the average is decided based on correlation method quality parameters and on statistical measures. This post-processing is discussed in Sect. 2.6.

\subsection{AATSR instrument}

The AATSR instrument has seven channels centered on the wavelengths of $0.555,0.659,0.865,1.61,3.7,10.85$, and $12.0 \mu \mathrm{m}$. The first four channels provide the ratio of reflected radiation to the incoming solar radiation at the top of the atmosphere, i.e., the TOA reflectance $R$, while the latter three channels provide information on the surface temperature via brightness temperatures $T$. The reflectance (visible) channels are used for the retrieval of aerosol properties using the ADV algorithm. The TIR channels can be used for the detection of the ash plumes, but also for the retrieval of aerosol properties such as AOD, using alternative algorithms (de Leeuw et al., 2013). For the plume top height estimates we use the stereo view of AATSR: the instrument has a near-nadir view and a $55^{\circ}$ forward view. The two views are in principle collocated 
at ground level. The plume height causes deviation from this in the direction along the satellite track, and the magnitude of the shift in this direction provides a way to estimate the plume height. Any of the channels can be used for the height estimate. The thermal infrared channels usually provide the highest contrast of the ash plumes with the background, and the $10.85 \mu \mathrm{m}$ channel is used by ACM by default. The horizontal resolution of AATSR is approximately $1 \mathrm{~km}$.

\subsection{Ash detection}

A volcanic ash plume can be detected using the brightness temperature difference (BTD) between two wavelengths, 11 and $12 \mu \mathrm{m}$ (Prata, 1989). In a first approximation, the brightness temperature difference, $\mathrm{BTD}=T_{11}-T_{12}$, is negative for volcanic-ash-contaminated pixels and positive for most other situations, such as meteorological clouds and clear-sky scenes. The optimal BTD threshold for ash detected is not always exactly 0 and, e.g., water vapor tends to increase BTD, hiding the ash signal (Yu et al., 2002). Also, false alerts can be caused, e.g., by desert dust or arctic haze. Although more detailed methods for ash detection exist for SEVIRI (Prata, 2013; Naeger et al., 2014) and for AIRS (Clarisse et al., 2010), for the purposes of this paper the simple BTD threshold method is sufficient.

\subsection{Height estimate principle}

The estimation of the ash plume top height is based on the stereo view of AATSR. The two AATSR views, a near-nadir and a $\sim 55^{\circ}$ forward view, are collocated at ground level. At higher altitudes, the two views are looking at different positions (in the along-track direction), with the difference increasing with increasing height. Thus, for an elevated feature with a detectable contrast to the background in both views, the height can be estimated by considering the apparent ground level difference in position between the two views (parallax).

A simplified illustration of the geometry is shown in Fig. 1. The cloud seems to be further away (with respect to the ground) in the forward view, as compared to the nadir view. The distance $d$ between the projections of the cloud on the Earth's surface in the two views gets larger with increasing cloud height $h$. The simplified picture shows the geometry for sub-satellite track only, for which the nominal nadir and forward-viewing angles are $\theta_{\mathrm{N}}=0^{\circ}$ and $\theta_{\mathrm{F}}=55^{\circ}$, respectively, and the height is obtained from $h=d / \tan 55^{\circ}$ (see Fig. 1). In the actual conical viewing geometry both viewing angles depend on the position of the pixel along the swath, and the height is obtained from $h=d /\left(\tan \theta_{\mathrm{F}}-\tan \theta_{\mathrm{N}}\right)$.

The height estimate process is automated by using a correlation method. The parallax is obtained by maximizing the correlation between the two views by allowing the forward view to be shifted. As a by-product, an estimate for the across-track wind can be obtained by allowing a two-

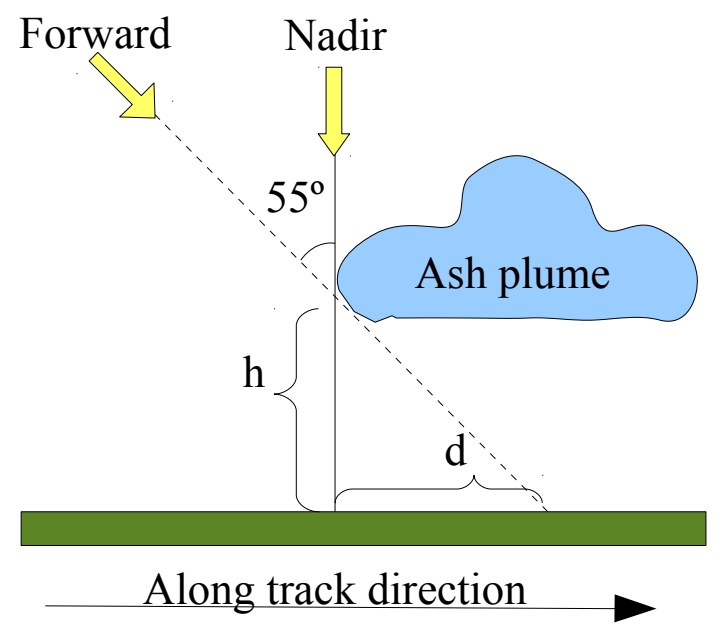

Figure 1. Cloud height estimate geometry. The edge of the cloud (at altitude $h$ ) is observed at different apparent positions at ground level in the two views, with distance $d$. With increasing height the distance increases.

dimensional shift and taking into account the time gap of approximately $135 \mathrm{~s}$ between the two views.

The ACM height estimate is based on the gradients of the measured brightness temperatures (or other quantities) rather than the measured values themselves. If the measured quantities remain constant over large areas, the height cannot be estimated using the stereo view methods. It should also be noted that the total TOA radiation is used in the correlation procedure; for partially transparent plumes or clouds the method might not work. If there are surface features with high contrast below the plume, they may dominate the correlation.

\subsection{Spatial-correlation plume height estimate}

We use an area-based cross-correlation method, which compares a small nadir view image, called the nadir view correlation window $(\mathrm{NCW})$, to a forward-view image of the same size (forward-view correlation window, FCW). The FCW is allowed to shift pixel by pixel in both along-track and acrosstrack directions, and the cross-correlation coefficient $C$ with the fixed-position NCW is calculated for each shift (Fig. 2). From the resulting correlation matrix, the forward-view shift with the highest correlation is selected, and it gives the cloud top (or plume top) collocation. While the along-track shift determines the height, the across-track wind speed component (at the plume top level) is obtained as a by-product from the across-track shift, taking into account the time gap of approximately 2 min between the two views. The known satellite-Earth geometry is used in converting the pixel shifts to height and wind speed estimates. 

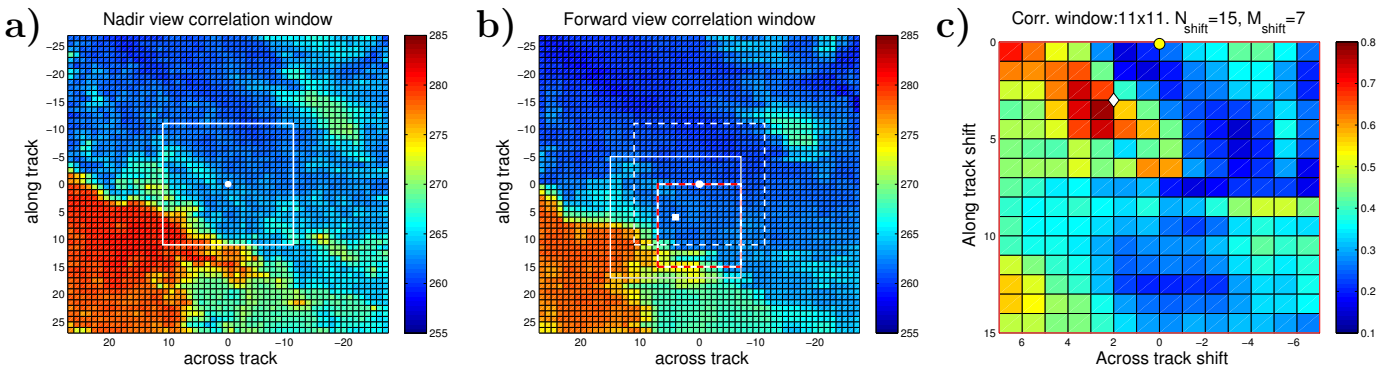

Figure 2. Illustration of the cross-correlation coefficient method using $10.85 \mu \mathrm{m}$ channel data $\left(T_{11}\right)$. The nadir view reference window is held in place (a), while the center point of the forward-view target window is allowed to move within the pre-set shift window shown as the red and white rectangle (b). The forward-view window scans all allowed shifts, and the resulting cross-correlation matrix is shown in panel (c). The maximum value of cross-correlation coefficient $C$ determines the best-fitting shift $(m, n)$ selected by the algorithm. In this example, the algorithm picks shift $(2,3)$ as the maximum correlation shift.

There are various alternative ways to define the crosscorrelation coefficient used in automatic height estimation. One of the first methods is described by Prata and Turner (1997) and is based on cross-correlating the measured data, normalized by rms values:

$C^{\prime}(x, y ; m, n)=\frac{\left\langle f_{\mathrm{N}}(x, y) f_{\mathrm{F}}(x+m, y+n)\right\rangle}{\sqrt{\left\langle f_{\mathrm{N}}(x, y)^{2}\right\rangle\left\langle f_{\mathrm{F}}(x+m, y+n)^{2}\right\rangle}}$,

where $f_{\mathrm{N}}$ is the measured GBTR value (gridded brightness temperature or reflectance) in the nadir view, and $f_{\mathrm{F}}$ is the corresponding value in the forward view, with pixel shift $(m, n)$ (in along-track $(n)$ and across-track $(m)$ directions). The coordinates $x$ and $y$ refer to the across-track (column) index and along-track (line) index, respectively (not to latitude or longitude). Here the average $\langle\ldots\rangle$ is defined (for both views respectively) as

$$
\langle f(x, y)\rangle=\sum_{i=-M}^{M} \sum_{j=-N}^{N} f(x+i, y+j) / N_{\mathrm{tot}},
$$

where the summation is over the correlation window (CW) and $N_{\text {tot }}$ is the total number of pixels in the window. The index $i$ runs through the across-track coordinate and the index $j$ correspondingly through the along-track coordinate of the $\mathrm{CW}$. The leading idea in the correlation method height estimate is then that the highest coefficient $C^{\prime}$ among all shifts gives the best-fitting pixel shift $(m, n)$, and the corresponding height is the most probable plume top height. However, it turns out that using Eq. (1) leads to a lot of noise in the end results. There are many possible reasons for this, including different background atmospheric effects for nadir and forward views, and generally noise in the TOA satellite data. It may also happen that there is simply not enough contrast between the plume and the background. Fortunately, there are some statistical tricks to remove part of the background noise and improve the results.

Instead of following the method of Prata and Turner (1997) as such, the approach adopted here is to consider the deviation of the measured values from the local average, instead of the measured values themselves (Muller et al., 2007; Zakšek et al., 2013; Fisher et al., 2013). The cross-correlation coefficient $C$ at point $(x, y)$ between the nadir and forwardview data is defined as

$C(m, n)=\frac{\left\langle\left(f_{\mathrm{N}}-\mu_{\mathrm{N}}\right)\left(f_{\mathrm{F}}(m, n)-\mu_{\mathrm{F}}(m, n)\right)\right\rangle}{\sigma_{\mathrm{N}} \sigma_{\mathrm{F}}(m, n)+\epsilon}$,

where the forward view is shifted by $m$ pixels in the acrosstrack direction ( $x$ axis) and $n$ pixels in the along-track direction ( $y$ axis). Here $\epsilon$ is a small constant ( 0.001 by default) used for numerical stability and to avoid amplification of noise. Here we have dropped the coordinates $x$ and $y$ for notational brevity. The correlation coefficients are in the range $-1 \leq C \leq 1$. The average $\mu_{\mathrm{N}}=\left\langle f_{\mathrm{N}}\right\rangle$ is defined as

$\mu_{\mathrm{N}}(x, y)=\sum_{i=-M}^{M} \sum_{j=-N}^{N} w_{i, j} f_{\mathrm{N}}(x+i, y+j)$,

where the summation is over the $\mathrm{CW}$ of size $N_{\text {tot }}=(2 N+$ 1) $\times(2 \mathrm{M}+1)$. The weight factor $w_{i, j}$ can be based on the distance from the center point $(x, y)$ for weighted average, or simply $1 / N_{\text {tot }}$ for arithmetic average. For the forward-view average, nominally associated with point $(x, y)$ but actually centered at the shifted point $(x+m, y+n)$, we have

$\mu_{\mathrm{F}}(x, y, m, n)=\sum_{i=-M}^{M} \sum_{j=-N}^{N} w_{i, j} f_{\mathrm{F}}(x+m+i, y+n+j)$.

This means that the whole forward-view correlation window associated with $(x, y)$ is shifted by vector $(m, n)$, as illustrated in Fig. 2. Naturally, the forward-view average is different for each shift $(m, n)$. The allowed pixels shifts $m$ and $n$ are predefined: $m \in\left\{-M_{\text {shift }}, \ldots, M_{\text {shift }}\right\}, n \in\left\{0, \ldots, N_{\text {shift }}\right\}$; only positive shifts are allowed for $n$, corresponding to positive heights.

The standard deviation $\sigma$ is defined as

$\sigma_{\mathrm{N}}=\sqrt{\left\langle\left(f_{\mathrm{N}}-\mu_{\mathrm{N}}\right)^{2}\right\rangle}, \quad \sigma_{\mathrm{F}}=\sqrt{\left\langle\left(f_{\mathrm{F}}-\mu_{\mathrm{F}}\right)^{2}\right\rangle}$ 
Table 1. Retrieval parameters, which need to be set prior to each retrieval. The default values are used in the results shown in this paper, unless otherwise indicated.

\begin{tabular}{llr}
\hline Abbreviation & Description & Default \\
\hline BTD & BTD $=T_{11}-T_{12}$ threshold & $0 \mathrm{~K}$ \\
CWS & Correlation window size & $11 \times 11$ \\
$N_{\text {shift }}$ & Maximum along-track shift & 15 \\
$\pm M_{\text {shift }}$ & Maximum across-track shift & 5 \\
Channel & Channel used in the retrieval & $T_{11}$ \\
\hline
\end{tabular}

for each of the views. The averages are defined as above, with shift $(m, n)$ implicitly assumed for the forward view.

The cross-correlation coefficient is calculated for each pixel $(x, y)$ and for each possible shift $(m, n)$. The shift corresponding to maximum $C$ is selected as the best-fitting shift for the given pixel $(x, y)$. The height corresponding to this shift $n$ is then calculated using appropriate satellite-Earth geometry. If $\phi_{1}$ and $\lambda_{1}$ correspond to the latitude and longitude of the original point $(x, y)$ and $\phi_{2}$ and $\lambda_{2}$ correspond to the shifted point $(x, y+n)$ (only along-track shift $n$ is considered in the height estimate), the along-track distance $d$ between these points can be approximated by

$d=\sqrt{\left[\cos \phi_{1}\left(\lambda_{1}-\lambda_{2}\right)\right]^{2}+\left(\phi_{1}-\phi_{2}\right)^{2}} R_{\mathrm{e}}$,

where $R_{\mathrm{e}}=6371.0 \mathrm{~km}$ is the mean Earth radius. The pseudoCartesian formula is adequate since we consider only short distances. The height is then obtained from

$h=\frac{d}{\tan \theta_{\mathrm{F}}-\tan \theta_{\mathrm{N}}}$.

The ACM height retrieval algorithm was written in Fortran and implemented as a part of the larger ADV/ASV aerosol retrieval algorithm. A typical run on an AATSR scene of 10000 ash-flagged pixels takes about $5 \mathrm{~min}$ on a regular desktop computer. A full scene height estimate takes much longer, so the automated ash detection is crucial for NRT volcano monitoring, as discussed in the introduction.

\subsection{Retrieval parameters}

The ACM height estimate algorithm uses several parameters, which affect the results. These include the size of the correlation window, the maximum allowed shifts for the forward view (both along-track and across-track, in pixels), the BTD threshold used for ash detection, and the channel used in the correlation method. The primary retrieval parameters are listed in Table 1.

\subsubsection{Brightness temperature difference}

As already discussed, the threshold $\mathrm{BTD}<0 \mathrm{~K}$ used for ash detection is not necessarily the optimal value for all cases.
Water vapor in the atmosphere increases the BTD, and thus a limit that is too low may cause some ash-contaminated areas to be missed. On the other hand, some phenomena, like arctic haze, may cause small negative BTD values and cause false alerts. For consistency, the threshold of $0 \mathrm{~K}$ is systematically used in this study.

In addition to the initial ash detection, the way in which the ash mask is used in the retrieval affects the results, particularly near the plume edges. The ash flags can be used in the correlation window: if a pixel in the window has its ash flag down, it may or may not be taken into account. If pixels from outside the plume are included, the resulting height may be lower than if non-ash pixels are excluded. On the other hand, if only ash-flagged pixels are used in the correlation window, there may not be enough data for reliable results near the plume edges. In the present approach, the non-ash pixels are included in the correlation window.

\subsubsection{Wavelength}

The height estimate results depend on the choice of the channel used in the correlation method. In Fig. 3 we show full scene height estimates for two different channels $-555 \mathrm{~nm}$ and $10.85 \mu \mathrm{m}$. The scene consists of an ash plume at $63^{\circ} \mathrm{N}$, $18^{\circ} \mathrm{W}$, extending to southeast, and high-altitude meteorological clouds in the northern part, and open ocean and low-level clouds. The $10.85 \mu \mathrm{m}$ channel is more sensitive to the water clouds, and the height estimate shows large elevated features in the northern part of the test scene. In particular, large parts of the water clouds on the northern part of the scene seem to lack sufficient contrast for the visible channel. The visible wavelength channel seems to detect only the thickest parts of the clouds and gives a lower average height for the scene. The average height (standard deviation) is $2.71(2.2) \mathrm{km}$ for $10.85 \mu \mathrm{m}$, and $2.06(2.1) \mathrm{km}$ for $555 \mathrm{~nm}$. Both channels detect heights of $5-7 \mathrm{~km}$ for the ash plume, but the shape and other details differ.

Results obtained with the $12 \mu \mathrm{m}$ channel are similar to those obtained with the $10.85 \mu \mathrm{m}$ channel (not shown). The thermal channel centered on $10.85 \mu \mathrm{m}\left(T_{11}\right)$ seems to be more sensitive to the ash plumes. For the results shown in this paper, the $10.85 \mu \mathrm{m}$ channel has been used.

\subsubsection{Correlation window size}

The correlation window size (CWS) used in matching the two views can have a large effect on the results. A large window can detect large features but miss smaller ones, while a smaller window can create a lot of noise (Zakšek et al., 2013). Figure 4 shows retrievals made with three different $\mathrm{CW}$ sizes. The small $5 \times 5 \mathrm{CWS}$ shown here contaminates the image with frequent high values. On the other hand, the large $13 \times 13$ CWS blurs the image, and the plume edge heights, for example, are a mixture of the actual plume top and the surrounding ocean or lower cloud layer. Using large 
a)

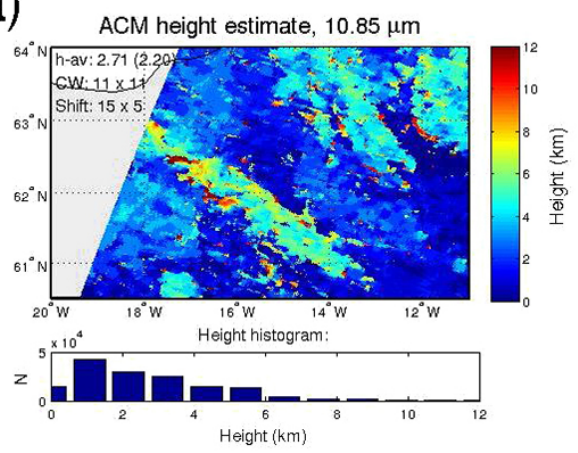

b)



Figure 3. Effect of wavelength on a full-scene height retrieval. The height maps show the ACM single-pixel height estimates (km a.s.l.) for an Eyjafjallajökull ash plume and its surroundings on 16 May 2010, obtained at two wavelengths, namely $10.85 \mu \mathrm{m}$ and $555 \mathrm{~nm}$. The height histograms below the maps show number of pixels within each height bin. See text for details.

a)

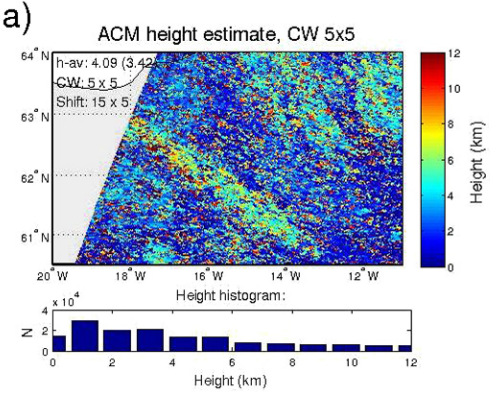

b)

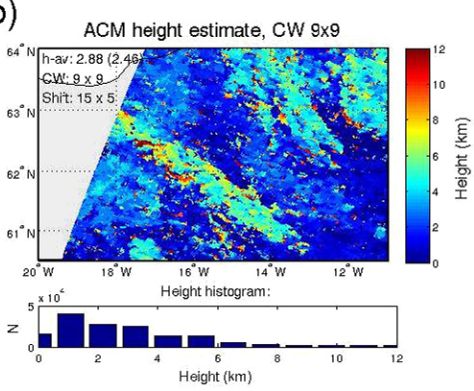

c)

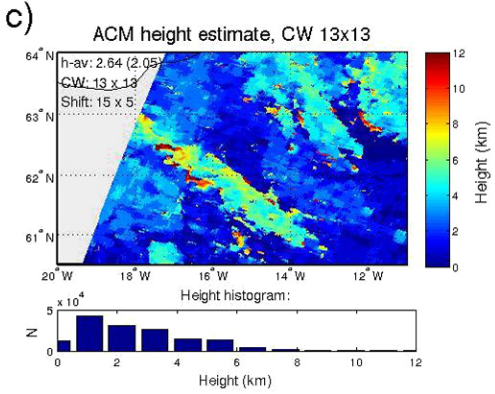

Figure 4. AATSR height estimate with three different CW sizes: $5 \times 5,9 \times 9$, and $13 \times 13$. The average height for the full scene varies in the range of $2.6-4.1 \mathrm{~km}$ for all CWS but settles at $\sim 2.6 \mathrm{~km}$ when CWS is increased. Also, the standard deviation of height decreases with increasing CWS. The height histograms below the height maps show how the fraction of high-altitude pixels decreases with increasing CWS.

CWS leads to lower average plume heights, presumably due to the contribution from the lower-level features surrounding the plume.

The default CWS in ACM is $11 \times 11$ pixels, but the algorithm simultaneously calculates two ancillary height estimates with smaller CWS $-9 \times 9$ and $7 \times 7$. As output, the algorithm provides the height estimates for all three CWS and the standard deviation of the height between them. Currently, the algorithm uses rectangular correlation windows and simple weights $w_{i, j}=1 / N_{\text {tot }}$ in the correlation procedure, Eq. (4).

\subsubsection{Allowed pixel shifts}

The forward-view correlation window is allowed to shift by $m$ pixels in the across-track direction, and by $n$ pixels in the along-track direction. The shifts are limited by conditions $m \in\left\{-M_{\text {shift }}, M_{\text {shift }}\right\}$ and $n \in\left\{0, N_{\text {shift }}\right\}$. The alongtrack shift is limited to positive values, corresponding to positive heights. Increasing the maximum allowed shift, $N_{\text {shift }}$, leads to an increase in the maximum height possible to obtain by the algorithm. A large enough $N_{\text {shift }}$ must be used so that the largest possible heights can be estimated reliably. Us- ing unnecessarily large $N_{\text {shift }}$ increases computation time and may also result in erroneous, unrealistically high values. Extreme along-track shifts can be removed in post-processing. In this work, we use $N_{\text {shift }}=15$, which corresponds to a maximum height of approximately $12 \mathrm{~km}$. Figure 5 shows how increasing $N_{\text {shift }}$ affects the results.

The across-track shift does not directly affect the height, but it is important in adjusting to the temporal changes in the image pair and to possible errors in the initial AATSR collocation. From Fig. 6 we see that if the across-track shift is not allowed, the height results would be very different. In this work, the across-track shift is limited by $M_{\text {shift }}=5$, which corresponds to maximum across-track wind components of approximately $40 \mathrm{~m} \mathrm{~s}^{-1}$. For comparison, Zakšek et al. (2013) report a maximum column shift of 20 pixels between two SEVIRI images, corresponding to approximately $22 \mathrm{~m} \mathrm{~s}^{-1}$.

\subsection{Post-processing}

The single-pixel height (SPH) values vary considerably from pixel to pixel. Part of this variation may be due to nonuniform structure of the ash plumes, but noise may also be caused by 

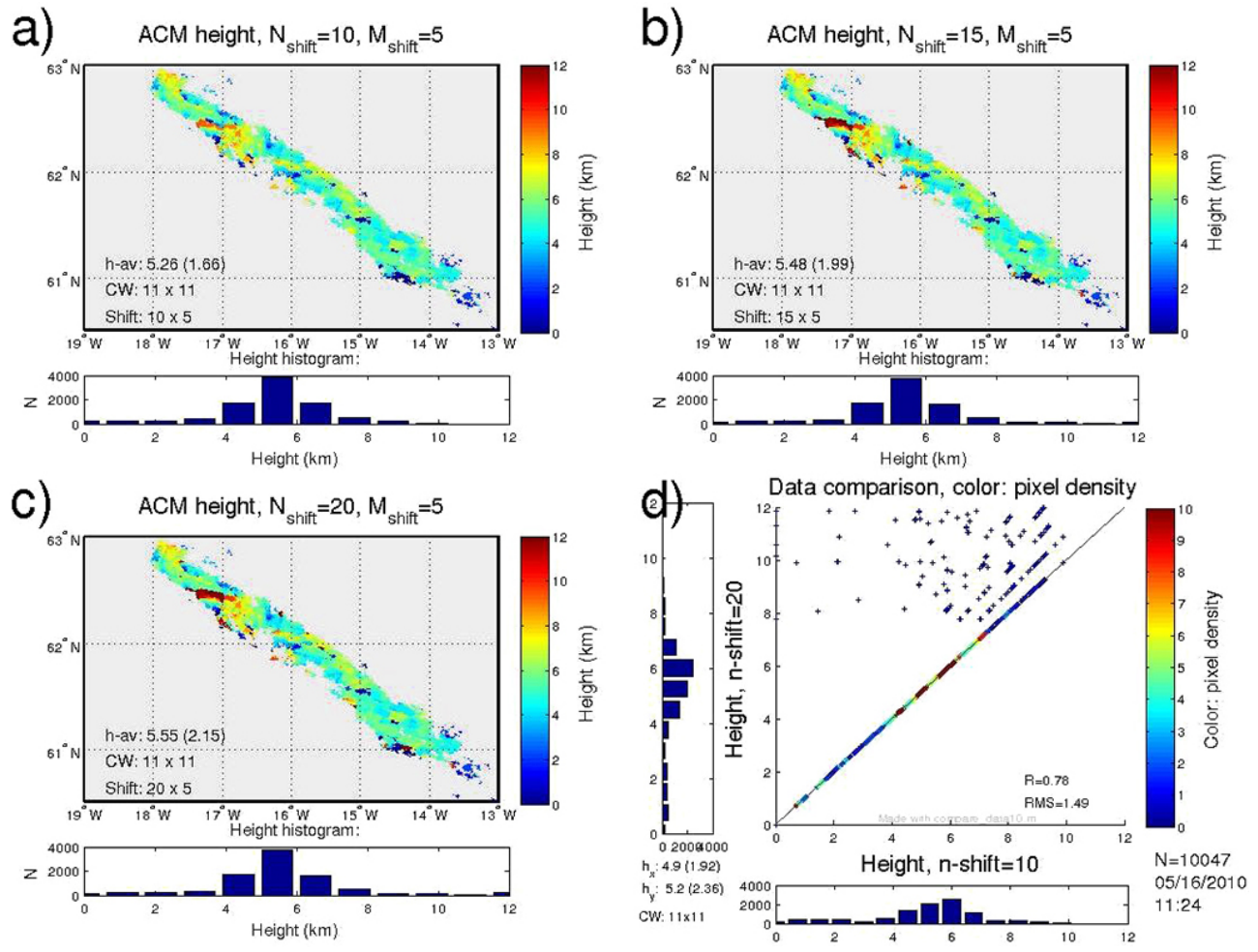

Figure 5. Effect of the maximum allowed along-track shift, $N_{\text {shift }}($ or $N$ ). Color scale is limited to $0--9 \mathrm{~km}$ although larger heights are possible, as seen in the height histograms (at the bottom of the figures). We see that most of the changes appear for the highest parts of the plume (as expected), but the scatterplot indicates other differences as well.

effects related to the different viewing angles and the time development of atmospheric features between the observations. To obtain more consistent results, we can use averaging over several pixels and statistical filtering. The ACM algorithm produces data on two levels: first, an SPH estimate is made for each ash-flagged pixel; then, a moving average is calculated for each ash-flagged pixel, using the SPH values of neighboring pixels. Only ash-flagged pixels are considered in the calculation of the average, and quality filters can also be applied before averaging. At the same time, we can calculate statistical variables related to the moving averaging window (MAW) and use those for further filtering. The resulting "best average height" (BAV) values are expected to be more representative than SPH data. However, the SPH data is also useful, since the quality filters often tend to remove a large portion of the original pixels.

Naturally, the average height results depend on the MAW size, possible weighting used in the averaging, and on the quality filters. In this section the effects of various parameters are discussed. The filtering parameters are listed in Table 2. Of course, the effectiveness of these parameters in improving the results can only be determined when reliable validation data is available. However, some conclusions can be made based on the variability of the heights; we expect the plume
Table 2. Parameters that can be used for filtering the height estimate data and the default values. In the ACM output, both the original unfiltered single-pixel heights and the filtered MAW-averaged heights are given. See text for details.

\begin{tabular}{llr}
\hline Parameter & Usage & $\begin{array}{r}\text { Default } \\
\text { threshold }\end{array}$ \\
\hline$C$ & $C>C^{\lim }$ & 0.5 \\
$\sigma_{\mathrm{c}}$ & $\sigma_{\mathrm{c}}>\sigma_{\mathrm{c}}^{\lim }$ & 0.15 \\
$\sigma_{\mathrm{CWS}}$ & $\sigma_{\mathrm{CWS}}<\sigma_{\mathrm{CWS}}^{\lim }$ & 20 \\
$\sigma_{\mathrm{av}}$ & $\sigma_{\mathrm{av}}<\sigma_{\mathrm{av}}$ & 3.0 \\
$\sigma_{m}$ & $\sigma_{m}<\sigma_{m}^{\lim }$ & 3 \\
$n_{\mathrm{av}}$ & $n>n_{\mathrm{av}}$ & 4 \\
\hline Extrema & on/off & On \\
Shadow & on/off & On \\
Cloud & on/off & On \\
\hline
\end{tabular}

top heights to be rather uniform on horizontal scales of $10 \mathrm{~km}$ or so.

The first three parameters in Table 2 - the correlation coefficient $C$; its standard deviation in the correlation matrix, $\sigma_{\mathrm{c}}$; and the standard deviation of the along-track pixel shift with respect to the correlation window size, $\sigma_{\mathrm{CWS}}-$ are related to the principle of the correlation method. The next three 

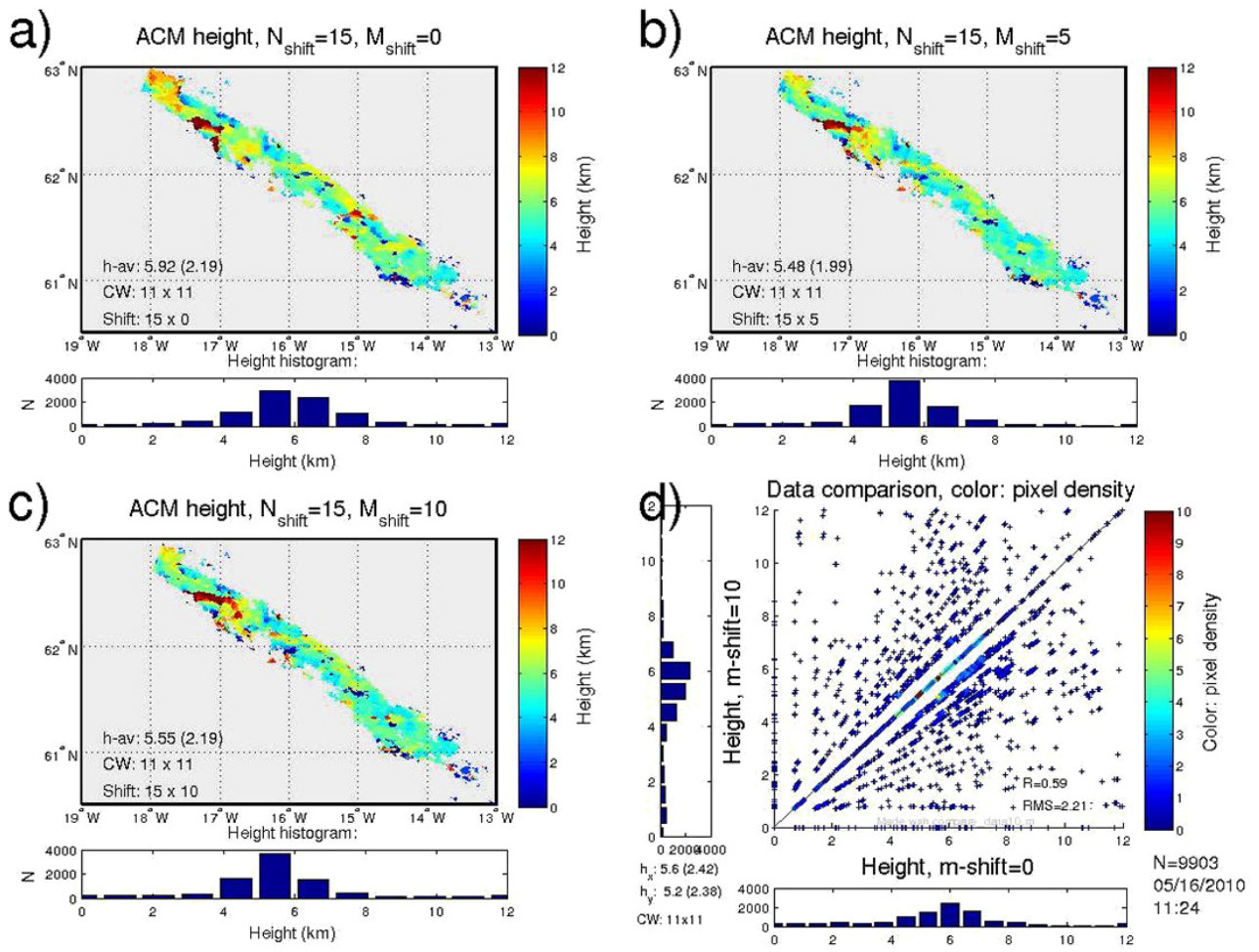

Figure 6. Effect of the maximum allowed across-track shift, $M_{\text {shift }}$ (or $\left.M\right)$, is much larger than that of $N_{\text {shift }}$. However, the difference between $M=5$ and $M=10$, for example, is already much smaller $(R=0.89$, not shown) than between $M=0$ and $M=10$, shown here $(R=0.59)$.

parameters - standard deviation of height within the MAW $\sigma_{\mathrm{av}}$; the standard deviation of the across-track shift within the MAW, $\sigma_{m}$; and the number of acceptable pixels $n_{\mathrm{av}}$ within the MAW - are related to the averaging. The three masks that can be applied to the SPH data are used to remove pixels where the algorithm chooses the maximum or zero alongtrack shift (extrema mask), pixels contaminated by water or ice clouds (cloud mask), or pixels where the forward view may be obstructed by a high feature earlier on the satellite track (shadow mask).

\subsubsection{Averaging window size}

In principle, there are two ways to do the averaging: increasing the pixel size or using the MAW technique. The former would reduce the computational load, but is less flexible, so the latter method is used in the ACM algorithm. The averaged height is given in full resolution, i.e., a separate value is calculated for each pixel. Although technically the resolution remains the same, the averaging blurs the details, as seen in Fig. 7. With an increasing MAW size the heights become more uniform but less detailed.

Since the height estimate is based on integer pixel shifts in the along-track direction, the resulting data is quantized, i.e., the height distribution consists of a small number of distinct heights. This is partially smoothed when the pixel shifts are converted to heights, since the height depends on the lat- itude and on the position along the satellite swath. The averaging further smooths the data, hiding the initial quantized nature of the retrieval. Figure 7 illustrates the smoothing using a moving averaging window.

When calculating the average heights, the standard deviations of height $\left(\sigma_{\mathrm{av}}\right)$ and across-track shift $\left(\sigma_{m}\right)$ within the MAW are also calculated. As discussed above, only ashflagged pixels are used in the averaging, and some of the ash-flagged pixels within the MAW may be removed before the averaging by applying various thresholds. The number of acceptable pixels used in the average $\left(n_{\mathrm{av}}\right)$ is recorded.

\subsubsection{Cloud screening}

The principle of the BTD threshold method for ash detection is simple: for volcanic ash $\mathrm{BTD}<0$ and for water clouds $\mathrm{BTD}>0$. In practice, the situation is not that simple. The proper threshold is not always $0 \mathrm{~K}$, as it may depend on, e.g., the water vapor content and the surface temperature. Since we concentrate on historic eruptions, the crude BTD threshold is usually sufficient for the present work. However, in mixed situations where thin water or ice clouds are situated above an ash plume, or when a thin ash plume lies above a lower cloud layer, the ACM algorithm may retrieve the height of the water/ice cloud layer, instead of the ash that causes negative BTD. Most of the usual cloud tests (Saunders et al., 1988; Koelemeijer et al., 2001) used 

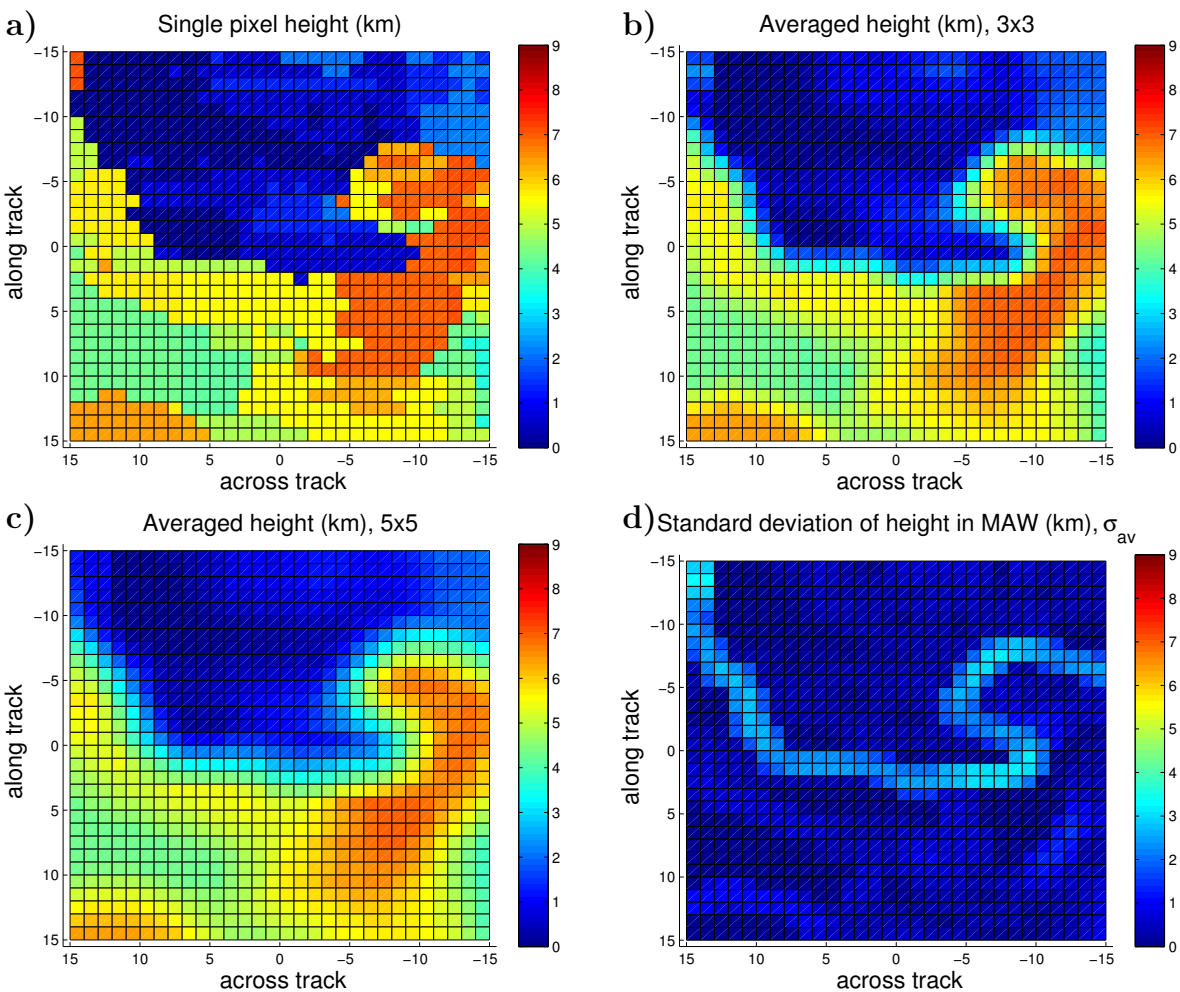

Figure 7. The effect of the averaging with a moving averaging window (MAW). (a) The initial single-pixel heights; (b) the MAW size $3 \times 3$ averaged values; (c) the MAW size $5 \times 5$ values. The averaging smooths the data, removing isolated peaks, but some details are lost. (d) The standard deviation of height within the MAW clearly indicates the plume edges.

in aerosol retrieval cannot be used in ash-specific retrievals, since they tend to misidentify ash plumes as clouds. However, assuming that the water/ice clouds are brighter than the ash plumes, we can use a reflectance test at $659 \mathrm{~nm}$ to remove ash-flagged pixels with possible cloud contamination. The cloud test analyses one AATSR scene and automatically determines a reflectance threshold, above which the pixel is flagged as cloudy (González, 2003). Figure 8 shows the effect of cloud mask on a test case. The false-color image of the scene (not shown) shows a water cloud layer below the ash plume around the central and southern parts of the plume.

The cloud mask can be applied to the data before averaging, but for many cases it is too stringent and removes most of the ash-flagged pixels. For the Eyjafjallajökull eruption the cloud mask removes on average more than $50 \%$ of the ash-flagged pixels. The effect of the cloud screening is case dependent, and manual inspection of the images is often required for optimal results.

\subsubsection{Shadow screening}

At a given position along the satellite track, the forward view may be blocked by high plumes earlier on the track. The high features cast a "shadow", the height of which decreases with distance. If the height of the "shadow" is higher than the height estimate given by the algorithm, the pixel is masked as "shadowed" (Fig. 9). The shadow mask is calculated from the initial single-pixel height estimates. For the Eyjafjallajökull eruption, the shadow mask typically removes $10-30 \%$ of the initial pixels.

\subsection{Error characterization}

Several assumptions are made in the height estimate method, and there are numerous sources of error. It is difficult to accurately quantify all the various error sources due to the nature of the correlation method. However, the quality parameters introduced in the previous section can be used to asses the contributions from different error sources to the height estimate.

\subsubsection{Resolution}

The nominal vertical resolution of the height estimate algorithm is approximately $1 \mathrm{~km}$, corresponding to a parallax of one pixel. Under the naive assumption of zero along-track wind, we estimate a typical error of 1-2 pixels, corresponding to $1-2 \mathrm{~km}$ in height. The default maximum shift in the along-track direction is 15 pixels, so an error of 2 pixels corresponds to a relative uncertainty of 13-200\%, depending on the height. This error estimate is based on the validation of the surface height estimate against topographic data 

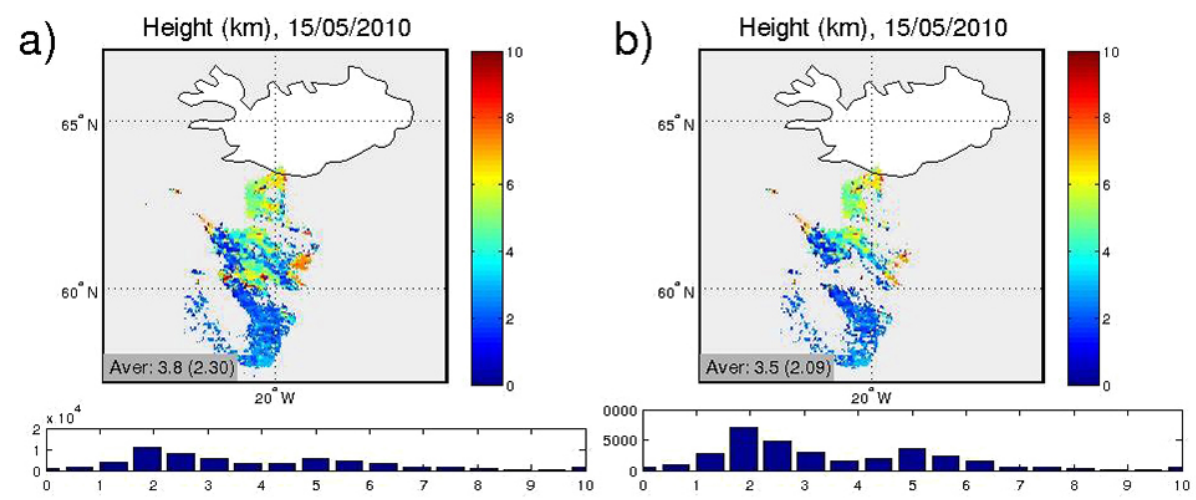

Figure 8. Eyjafjallajökull eruption 15 May 2010. We show the effect of removing the ash pixels flagged as cloudy by $659 \mathrm{~nm}$ reflectance cloud test. In panel (a) we show all SPH values, while in panel (b) the cloud-flagged pixels have been removed. The average height decreases from 2.40 to $2.29 \mathrm{~km}$ when the clouds are removed, but the height histograms (below the maps) show that there are no dramatic changes in the height distribution.
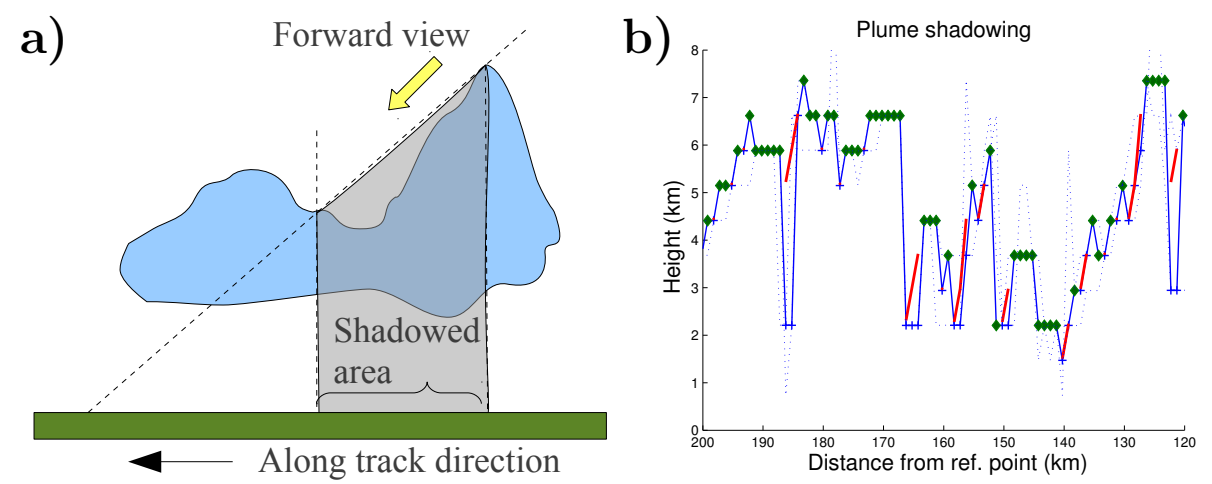

Figure 9. (a) Principle of the plume shadowing. A high feature can block the forward view (for lower features) in the along-track direction. A reliable height estimate cannot be obtained for pixels in the shadowed area. (b) An example of shadow masking, an along-track height profile. The blue line shows the initial height estimate. The high features block the forward view on the areas indicated by the red lines, preventing the height estimate. The green dots indicate heights accepted after the shadow masking. Note that in the shadowed areas the method typically suggests uniform, underestimated heights.

(Sect. 3.1). In addition, there are several error sources that may have a more significant contribution to the total error. These are discussed in more detail below.

The horizontal resolution (pixel size) is approximately $1 \mathrm{~km}$, with the exact value depending on latitude and on the position along the swath. The algorithm output contains height estimates in the full resolution. A moving average value over 25 (by default) neighboring pixels is also provided for each pixel, with the same nominal resolution.

\subsubsection{Correlation method quality}

The quality of the correlation method height estimate can be assessed using several quantities. First, the correlation coefficient $C$ of each pixel is a natural measure of the quality of the estimate: for pixels with $C$ approaching 1, we have high confidence in the reliability of the estimate, while pixels with $C<0.5$ are removed by default filters. (By "correlation coefficient of a pixel" we mean the maximum cross-correlation coefficient over all possible shifts for the $\mathrm{CW}$ centered on the said pixel.) Low values of $C$ may occur due to many reasons. Large changes in the plume shape and position in the approximately $130 \mathrm{~s}$ time gap between the views is one possible cause for a low $C$ value. Poor correlation can also be caused by effects due to differences in the viewing geometry; the forward view has a longer light path and is more affected by an ash layer. Also the underlying surface texture may have different relative contributions in the two views.

The second parameter that can be used in quality assessment is the standard deviation of the correlation coefficient, $\sigma_{\mathrm{c}}$ within the correlation window. If $\sigma_{\mathrm{c}}$ is low, i.e., if the amount of shift of the forward window does not make much difference, we cannot trust the results. This may happen, for example, if the scene considered is covered by a large cloud mass, with little or no high-contrast features that could be matched between the two views. Another possible scenario 

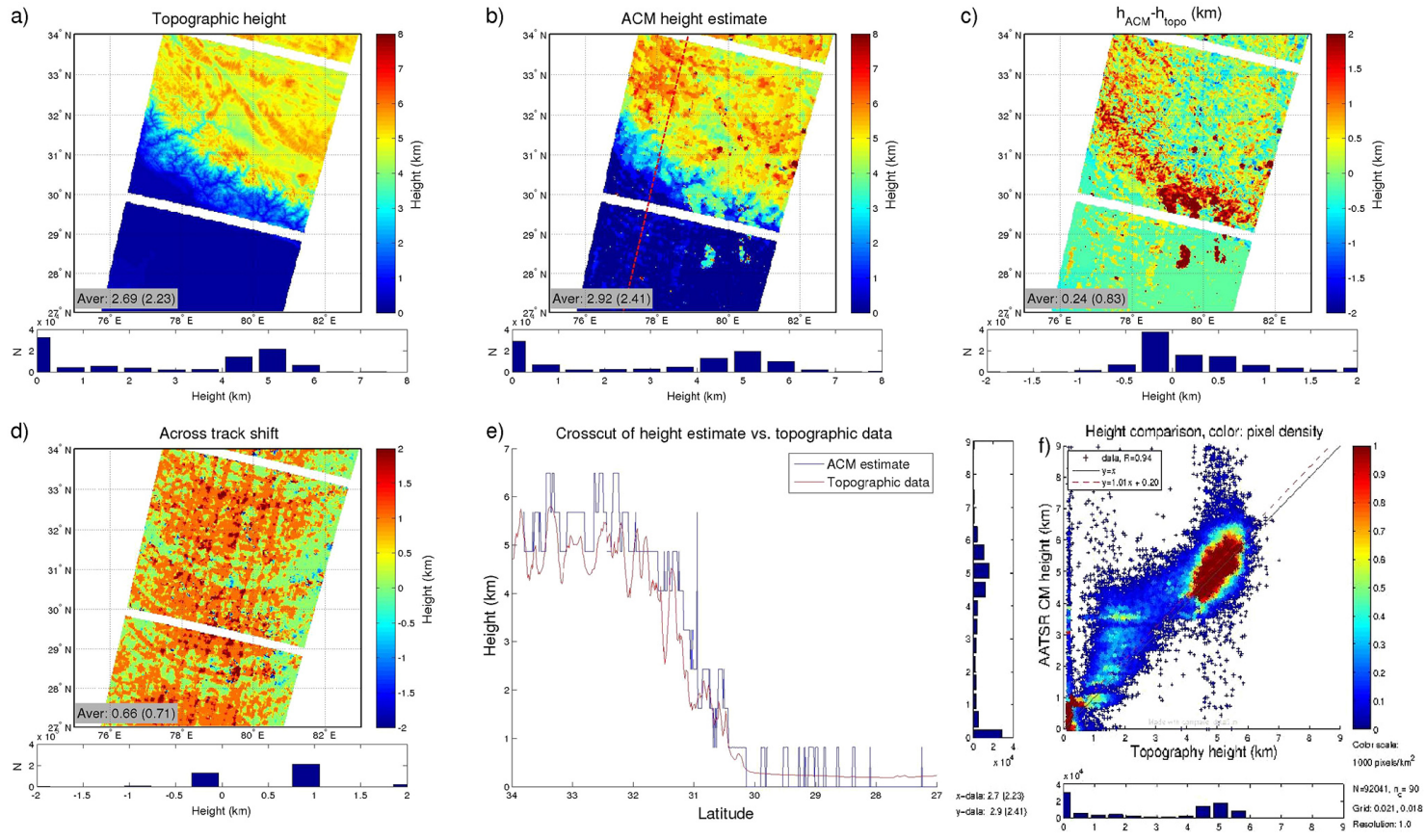

Figure 10. (a) Topographic data over the Himalayas, (b) AATSR height estimate, (c) their difference, (d) the across-track pixel shift, (e) a crosscut height profile, and (f) the scatterplot for topographic height and ACM estimate. Some cloud contamination can be seen in the ACM height estimate, particularly on the southern edge of the mountain range. These cause the largest differences, seen as the red areas in panel (c), narrow peaks in panel (e), and as large scatter in panel (f). The crosscut is indicated in panel (b) as the dashed red line. The vertical resolution of roughly $1 \mathrm{~km}$ is clearly seen in the height estimate profile (e), as well as the jumping of the algorithm between 0 and $1 \mathrm{~km}$ in the lower plains. Panel (d) shows features resembling the conical scanning geometry of AATSR and may indicate ground level collocation errors.

where $\sigma_{\mathrm{c}}$ might be low is glinting sea surface, where any detectable features may be hidden in the noise.

\subsubsection{Multilayer structures and transparency}

Errors due to multilayer structures and transparent ash plumes are particularly difficult to quantify. The height estimate algorithm provides the height of the dominating feature in the scene, which may not necessarily be the ash plume but, e.g., an underlying water cloud or the ground surface. The correlation method relies on the assumption that the detected ash plume is the dominating feature in the scene so that the algorithm can reliably track and collocate the plume features. However, if the ash plume is thin and transparent, the underlying surface texture may dominate the cross-correlation. Thus the algorithm may not always find the plume top height but the height of some other feature.

The noise seen in the initial SPH data may be partly due to the algorithm jumping between the plume top level and surface- or cloud-level collocation. The variation of SPH within the MAW or between different CWS can be used as indicators of such jumping between features at different heights. The algorithm attempts to minimize the occurrence of such cases by applying thresholds to $\sigma_{\mathrm{av}}$ and $\sigma_{\mathrm{cws}}$.

\subsubsection{Collocation}

There is a known collocation error between the ground-level nadir and forward views of AATSR (ESA, 2013) of two pixels in the along-track direction and one pixel in the acrosstrack direction (before the third reprocessing). This collocation error was independently observed when the ACM height estimate results were compared to topographic data, and a systematic correction is applied. However, it appears that the collocation is still not perfect, and artificial features (resembling the AATSR geometry) are seen in the height estimate results when applied to full AATSR swath (see Fig. 10d). In particular, the across-track shift data indicate that a further rectification of one pixel in the across-track direction would be necessary. The algorithm adjusts automatically in the across-track direction by allowing a shift of the forward view in this direction. The absolute value of the shift is not directly needed in calculating the height estimate, so a systematic error in the across-track collocation is not critical. However, the across-track shift can be used to estimate the across-track wind component, which in turn can be used as a proxy for the along-track wind component, as discussed below. 


\subsubsection{Wind}

An along-track wind component can cause an along-track shift of features between the forward and nadir view in the approximately 2 min time gap between the forward and nadir overpasses (Prata and Turner, 1997). A best-fit parallax obtained by the correlation method can be caused partly by the height of the cloud and partly by its motion. Assuming that the parallax is due to height alone can cause a significant error. An along-track wind speed component of approximately $8 \mathrm{~m} \mathrm{~s}^{-1}$ can cause a parallax of one pixel, or an error of $\sim 1 \mathrm{~km}$ in the height estimate.

The across-track shift obtained as a by-product in the height retrieval can be used as a qualitative indicator of possible errors due to along-track wind, if further information on the wind direction is available. As an example, a rough estimate of the wind speed can be made from Fig. 6 . For the ash plume $(\mathrm{BTD}<0)$ the average across-track shift is 1.5 pixels (not shown), corresponding roughly to $11 \mathrm{~m} \mathrm{~s}^{-1}$ wind speed. From the direction of the ash plume relative to the swath, we can estimate that the along-track component is roughly onethird of this, i.e., smaller than $4 \mathrm{~m} \mathrm{~s}^{-1}$. This corresponds to an along-track shift of less than a pixel, and thus it is not likely that the along-track wind causes very large error in the height estimate in this case. In general, if we assume the along- and across-track wind components to be equal, the typical acrosstrack shift of one pixel indicates an uncertainty of $\sim 1 \mathrm{~km}$ in the height.

The ash plume may also change its shape and altitude between the two observations. Prata and Turner (1997) argue that the vertical updraft as such is not a major source of error, since the height information is essentially obtained at the time of the forward overpass. Also, since the correlation window size is typically on the order of $10 \mathrm{~km}^{2}$, modest changes in the cloud morphology should not have a large effect on the height estimate.

\section{Validation and comparisons}

The height estimates should be validated against independent in situ sources and compared to available remote sensing data. In this section we compare the ACM height estimates to five independent sources. Since the algorithm can be used to estimate the height of any elevated feature, including ground surface, we can verify the method principle against surface topography data. We also use two satellite-based instruments, MISR and CALIOP, for comparison. In addition, we use data from two ground-based sources for the Eyjafjallajökull eruption, the Keflavík weather radar, and a database derived from web camera imagery.

\subsection{Topography}

Comparison against topographic data is the best way to validate the principle of the algorithm. Accurate information on the surface height is available globally at high resolution and without the need to consider timing. The errors in validation data are negligible considering the nominal resolution of $1 \mathrm{~km}$ of the height estimate.

The ACM algorithm aims at providing height estimates for elevated atmospheric features such as clouds and ash plumes, and thus validation against ground targets is not sufficient. While the cloud-free ground surface is opaque, offering an ideal target for the correlation method, clouds and plumes can be partially transparent and have a complicated three-dimensional structure with multilayer features. However, the overwhelming availability and quality of the topographic data is valuable for testing the basic principles of the height estimate method.

For this test case we have chosen an almost cloudfree scene over the Himalayas on 4 May 2010 at 04:19 (all times in this article are given in UTC), AATSR orbit ATS_TOA_1PRUPA20100504_041906. The surface heights are obtained from http://topex.ucsd.edu/cgi-bin/get_ data.cgi/. The area has sufficient contrast in both surface reflectivity and brightness temperatures for the tests to work in principle: the mountain tops are cold and snow covered, while the surrounding terrain has darker surfaces and higher temperatures. Although we searched for least possible cloud cover, some uncertainty is still caused by cloud contamination. The difficulty is that the standard cloud tests mask the mountain tops as cloudy, since they are bright and cold, and it is difficult to distinguish between the actual clouds (which are an inconvenience here) and the mountain tops (which we are studying).

In the comparison we use the AATSR grid and average the high-resolution surface topography data around each AATSR pixel. The per-pixel comparison shows excellent agreement between the ACM height estimate and the surface height data, considering that some cloud contamination is present (Fig. 10). The scatterplot in Fig. 10f shows fair overall agreement, with a correlation coefficient of 0.96 . Cloud contamination can be seen in the scatterplot as peaks in the ACM data. Some of the features of the mountain range are captured by the ACM, but most details are blurred by noise in the ACM data. The crosscut height profile in Fig. 10e shows the agreement between ACM and topography data and also illustrates the ACM vertical resolution of approximately $1 \mathrm{~km}$. The ACM algorithm shows slight overestimation of heights on the southern edge of the mountain range. This may be due to cloud contamination, but it may also be related to the AATSR viewing geometry: the southern slope is facing "away" from the forward view of AATSR, moving from north to south. A surface shadow mask was not applied to the ACM data, although the AATSR forward view may be obstructed by some of the steep slopes. 
Table 3. Number of the common pixels $(N)$ for the MPHP and ACM data, the corresponding average heights for the full original plumes (orig) and for common pixels only (comm), and the correlation coefficient $R$. Only the SPH values for ACM are shown here.

\begin{tabular}{lrrrrrr}
\hline Date & $N$ & $h_{\mathrm{acm}}^{\text {orig }}$ & $h_{\mathrm{mphp}}^{\text {orig }}$ & $h_{\mathrm{acm}}^{\text {comm }}$ & $h_{\mathrm{mphp}}^{\text {comm }}$ & $R$ \\
\hline 15 Apr & 2856 & 4.63 & 2.43 & 5.67 & 2.66 & 0.21 \\
18 Apr & 1008 & 2.30 & 1.81 & 3.52 & 2.16 & -0.31 \\
19 Apr & 3285 & 1.77 & 0.94 & 1.81 & 1.32 & -0.08 \\
03 May & 525 & 5.04 & 3.69 & 5.97 & 3.79 & -0.36 \\
7 May & 3814 & 3.08 & 3.88 & 3.16 & 3.28 & 0.53 \\
12 May & 1188 & 4.86 & 5.26 & 4.25 & 5.26 & -0.20 \\
13 May & 13741 & 3.55 & 2.62 & 3.32 & 2.57 & 0.12 \\
16 May & 2995 & 5.45 & 6.13 & 5.53 & 6.06 & 0.19 \\
\hline
\end{tabular}

\subsection{MISR}

MISR, with its nine views, is an optimal instrument for height estimates of atmospheric features. Unfortunately, for our purposes it has limited usability due to its lack of TIR channels for ash detection. However, it provides useful comparison data for the ACM height estimates. There are a number of M-series height estimate algorithms and various tools for cloud top height estimates (Muller et al., 2002, 2007; Fisher et al., 2013). A useful tool for analyzing the plume properties using MISR data, the MISR INteractive eXplorer (MINX), is available as open-source software (Nelson et al., 2013). MINX offers better resolution than the operational MISR product, but requires manual detection of the ash plumes. Plume top heights obtained with MINX have been compared with thermal height estimates and ground-based radar results by Ekstrand et al. (2013). Particularly interesting for our work is the MISR Plume Height Project (NASA, 2013), where the height estimates are calculated for some manually selected ash plumes. In the following we compare the height estimates made with the ACM to the MISR Plume Height Project (MPHP) height estimates.

In Table 3 we show the average heights for both AATSR and MISR data for the eight cases where overlapping data exists. In the comparison only common pixels have been used, i.e., data is limited by both the MPHP handmade plume polygon and by the AATSR BTD $<0 \mathrm{~K}$ threshold. We have used the MPHP grid, and averaged the ACM data within a $4 \mathrm{~km}$ radius from the grid point. The number of common MPHP pixels $N$ is given in the table. The pixel-by-pixel correlation coefficients $R$ are also given for each case, and we see that the correlation is poor. This is not surprising, given that there is a time gap of approximately $2 \mathrm{~h}$ between the overpasses, during which the plumes may have shifted. The averaged plume heights are a better starting point for the comparison, but some collocation and ash identification issues remain. For example, the common pixels (those that pass the AATSR $\mathrm{BTD}<0 \mathrm{~K}$ thresholds and are within the MPHP polygon) may not give representative subsets of the plume height data.
A more reasonable comparison might be achieved by manually selecting corresponding plume areas from both data, taking into account the horizontal motion of the plume during the time lapse, but such selection is prone to interpretation bias and is not conducted here.

The heights averaged over common pixels are similar for all cases, except the first one on 15 April. For this case, the MPHP plume polygon is not strictly limited to the ash plume, but contains surrounding sea surface areas as well. This is seen as the much smaller average height than for ACM in the comparison.

In Fig. 11 we show MPHP and ACM data, and their comparison, for an Eyjafjallajökull ash plume just south of Iceland on 16 May 2010. For AATSR, we use the SPHs; comparison with the BAV data gives only slightly improved results. For the test case data, limited by both the MPHP plume area and by the AATSR BTD threshold, the average height (standard deviation) is $6.1(0.57) \mathrm{km}$ for MPHP and $5.5(1.15) \mathrm{km}$ for ACM. Although the heights averaged over the whole plume are not too different, the pixel-by-pixel scatterplot shows poor agreement. Part of this can be explained by the $\sim 2 \mathrm{~h}$ time gap between the overpasses; from the false-color image (not shown) we can clearly see that the plume has shifted to the north between the AATSR and MISR images, which is not taken into account in the scatterplot. We see that the MISR results show rather uniform heights, whereas much more variation is seen in the AATSR data.

There are several differences in acquisition of the two data sets. Although the correlation algorithms are based on the same principles, there are differences in the normalization procedures, correlation window sizes, and other retrieval parameters. The MPHP data is obtained using a visible wavelength channel $(671 \mathrm{~nm})$, while for AATSR we use a TIR channel $(10.85 \mu \mathrm{m})$. Also, for the MISR data smaller viewing zenith angles (VZA) are used: MPHP typically uses six of the oblique cameras, labeled A $\left(26.1^{\circ}\right), \mathrm{B}\left(45.6^{\circ}\right)$ and C $\left(60.0^{\circ}\right)$, paired with the nadir view camera for in the correlation method. A lower VZA leads to lower vertical resolution, and thus to more uniform plume heights for MPHP data. On the other hand, a larger VZA leads to increasing differences in the viewing geometry and increasing errors due to plume shadowing and different light path lengths. There are windcorrected height estimates available for the MISR data, but in the comparison we have used only data without wind correction.

Further work, including wind corrections and the use of visible wavelength for ACM, is needed in order to understand the remaining differences between ACM and MPHP results, but this is beyond the scope of this paper. It is also possible to adapt the ACM algorithm for use with MISR data, which would allow a more detailed comparison. 
a)
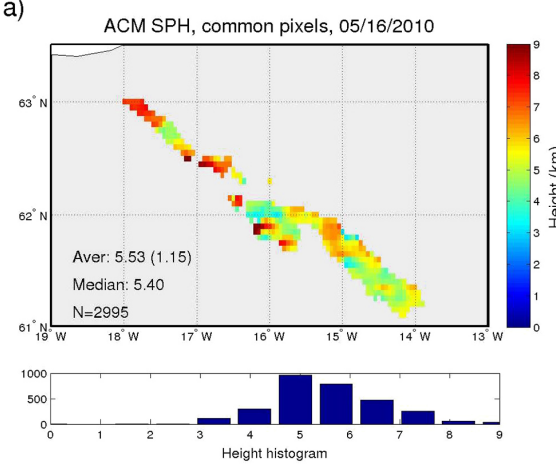

c)

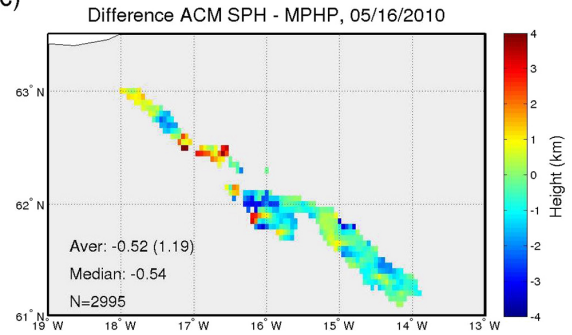

b)
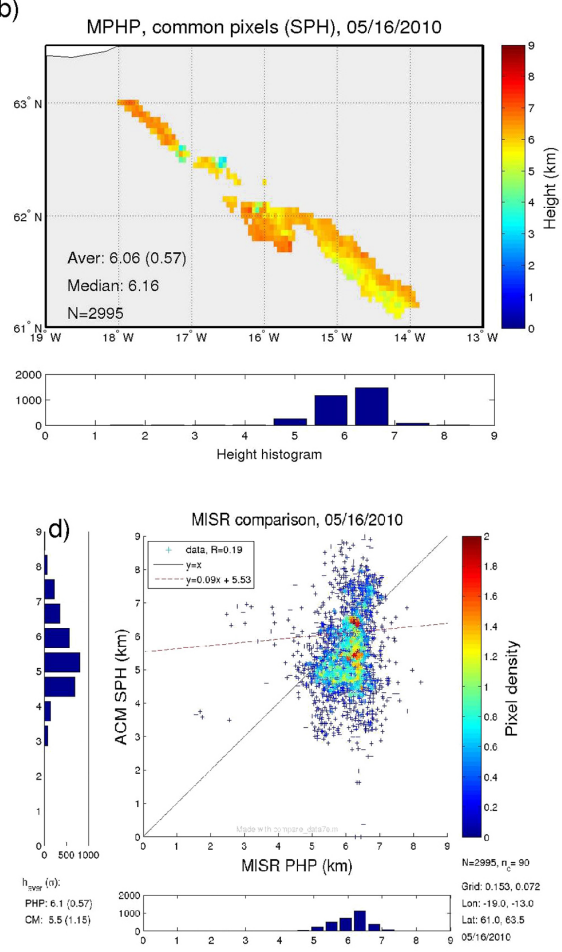

Figure 11. The MPHP and ACM (SPH) plume heights and their difference, limited by both the MPHP plume and AATSR-detected ash plume $(\mathrm{BTD}<0 \mathrm{~K})$. AATSR gives $0.5 \mathrm{~km}$ lower heights on average, with significantly more variation $\left(\sigma_{h}=0.6 \mathrm{~km}\right.$ for MISR and $\sigma_{h}=1.2 \mathrm{~km}$ for AATSR), as can be seen from the height histograms (below the height maps). The differences are centered roughly on 0 , but the scatterplot shows poor pixel-by-pixel correlation $(R=0.2)$ between the instruments.

\subsection{CALIOP}

The lidar data from the CALIOP on the Cloud-Aerosol Lidar and Infrared Pathfinder Satellite Observations (CALIPSO) platform (Winker et al., 2007) gives accurate ash plume heights, but with its limited coverage it is difficult to find even remotely simultaneous overpasses with AATSR, where ash is present. One such case is found southwest of Iceland, where a large ash cloud is observed by AATSR on 7 May 2010 at 22:51. The plume is crossed by CALIPSO some $5 \mathrm{~h}$ later on 8 May 2010 at 04:04. From hourly SEVIRI data (Prata and Prata, 2012; Prata, 2013) between 23:00 7 May and 04:00 8 May we see that the ash plume, which initially coincides with the plume observed by AATSR, moves south by approximately $2^{\circ}$ in $5 \mathrm{~h}$ (Fig. 12). Considering this, there is remarkable agreement between the ACM height estimate and the CALIOP sounding.

The CALIOP data shows three thicker ash layers approximately at $10,7.5$, and $5 \mathrm{~km}$ heights, and ACM shows data at similar altitudes. There are also lower-level cloud structures at $\sim 3$ and $\sim 1 \mathrm{~km}$ levels, which are picked out by $\mathrm{ACM}$ at the edges of the plume. It is possible that the vertical structure of the plume is changed in the $5 \mathrm{~h}$ between the observations, but the smooth transition of the plume with only modest changes in the horizontal shape (as observed in the six SEVIRI images acquired hourly) imply that drastic changes have not necessarily occurred. A few other similar cases of near simultaneous overpasses can be found, with decent agreement between the data but with some collocation issues remaining.

\subsection{Weather radar and webcam}

Ground-based plume top height data for Eyjafjallajökull includes Keflavík weather radar plume top height estimates and time series of plume top altitudes constructed from web camera images (Arason et al., 2011). These data give one height value for each time, for the maximum plume top height over the volcano. From all the AATSR ash plume cases for the Eyjafjallajökull eruption, only 13 have data over the volcano: six in daytime and seven cases in the nighttime retrievals. In Fig. 13 we compare the ACM data, averaged over all ashflagged pixels within $50 \mathrm{~km}$ from the volcano, with the radar and web camera data. Generally the ACM heights follow the in situ data well, considering that the averaging smooths the somewhat noisy ACM single-pixel height data. Note that the weather radar data has a minimum height of $2.5 \mathrm{~km}$ and the web camera data has a maximum height of $5.2 \mathrm{~km}$ a.s.l. at the volcano. 

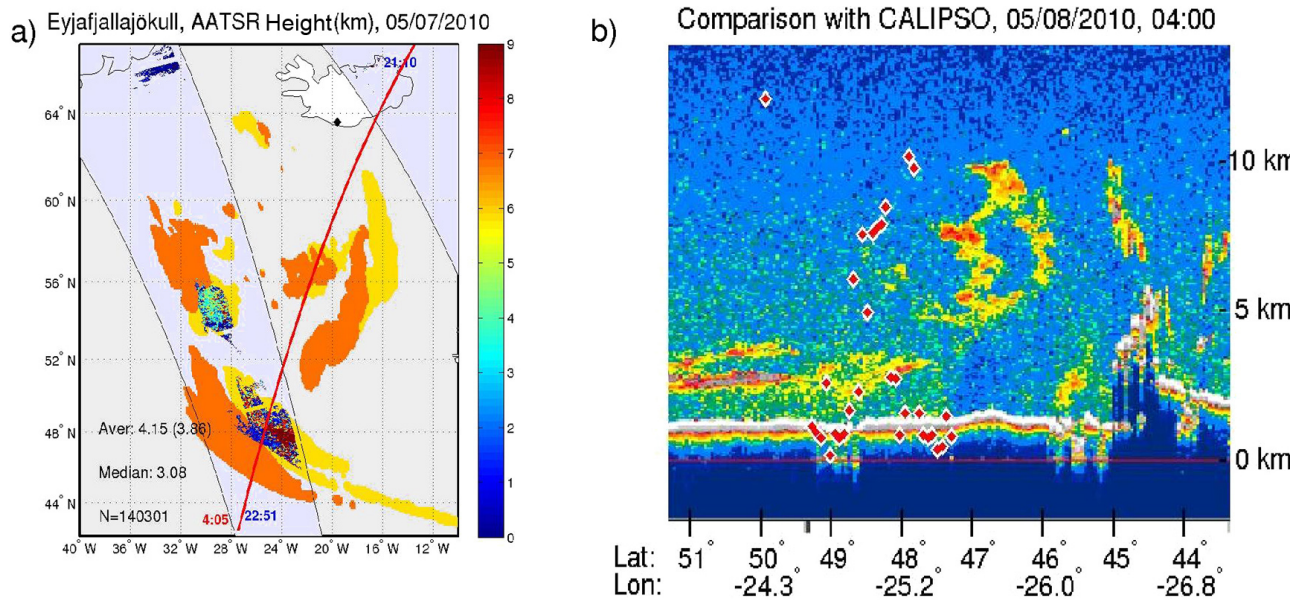

Figure 12. Eyjafjallajökull eruption, 7-8 May 2010; a near-simultaneous overpass of AATSR and CALIPSO over a large ash cloud. (a) The shaded blue area shows the AATSR swath on 7 May at approximately 22:51, while the red line shows the CALIPSO track on 8 May at approximately 04:05. The color-coded pixels show the ACM height estimate. The yellow area shows ash plume detected by SEVIRI on 7 May at 23:00, which coincides with the ACM plume (within the AATSR swath). The orange area shows the plume observed by SEVIRI $5 \mathrm{~h}$ later, at the time of CALIPSO overpass. (b) CALIOP backscatter profile on 8 May at 04:00, with the ACM height estimates from 7 May 22:51 shown by the red symbols. The ash plume is seen between 46 and $48^{\circ} \mathrm{N}$ in the back scatter data, while for ACM it was observed near $48-49^{\circ} \mathrm{N}$.

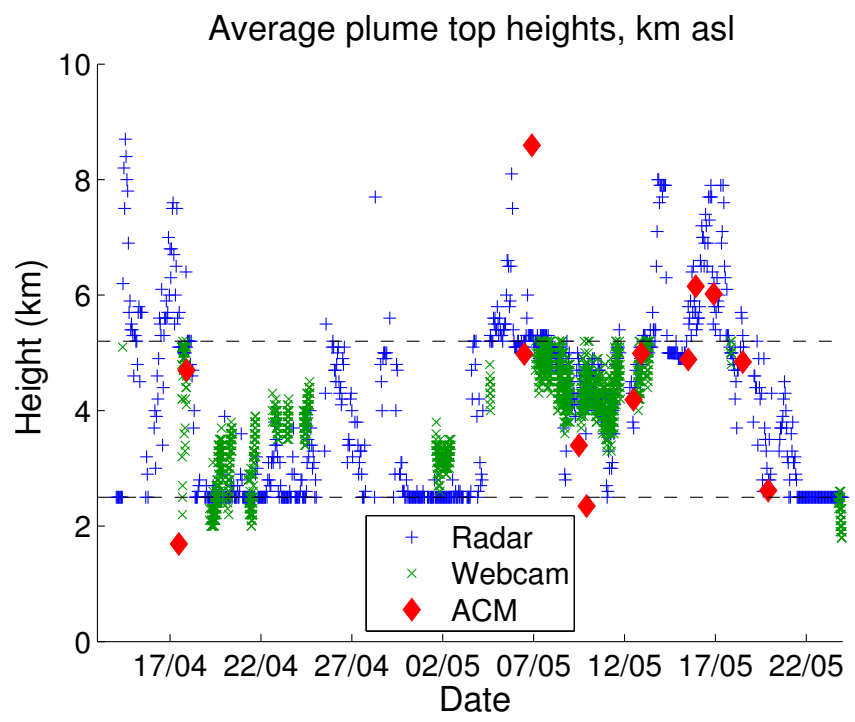

Figure 13. Ground-based plume top height data for the Eyjafjallajökull plume from the Keflavík weather radar and a web camera at Hvolsvöllur (Arason et al., 2011), combined with the AATSR height estimates near the volcano. The radar data is limited from below by $2.5 \mathrm{~km}$ and the web camera data is limited from above to $5.2 \mathrm{~km}$ (dashed black lines). The ACM data is an average over all ash-flagged single-pixel heights within $50 \mathrm{~km}$ from the volcano (both day- and nighttime data).

\section{Case study: Eyjafjallajökull}

As an example, we apply the AATSR correlation method height estimate algorithm to the Icelandic Eyjafjallajökull eruption in 2010. The course of eruption and ash dispersal is described, e.g., by Gudmundsson et al. (2012). Ash detection and mass load retrieval by SEVIRI for the eruption period is described by Prata and Prata (2012), and a detailed dispersion model study, including plume height information, is presented by Stohl et al. (2011). Ash identification and retrieval of ash properties using MISR are described by Kahn and Limbacher (2012). Volcanic ash plume top heights for several days in April during the eruption are estimated using combined SEVIRI and MODIS data by Zakšek et al. (2013). The eruption can be divided into three periods: in the first phase (14-17 April) ash was spread to the southeast over northern and central Europe; in the second phase (18 April4 May) less ash was produced and it was only observed near Iceland; in the third phase (5-18 May) the eruption intensity increased again, and ash was dispersed in all directions and over large distances.

For the first phase of the eruption we have data on 3 days. On 15 April a narrow plume is observed near the Faroe Islands at $3-5 \mathrm{~km}$ height, extending from west to east. On 16 April two distant ash clouds were observed over Poland with heights of around $4 \mathrm{~km}$ and $1 \mathrm{~km}$. For the second eruption phase, we have no AATSR observations with the $\mathrm{BTD}<0 \mathrm{~K}$ threshold. However, this lack of detected ash is partly due to the threshold being too strict for the steam-rich plumes rather than due to the absence of ash. The water vapor within the ash plume tends to increase BTD, thus preventing 
a) Eyjafjallajökull, AATSR Height $(\mathrm{km}), 06 / 05 / 2010$

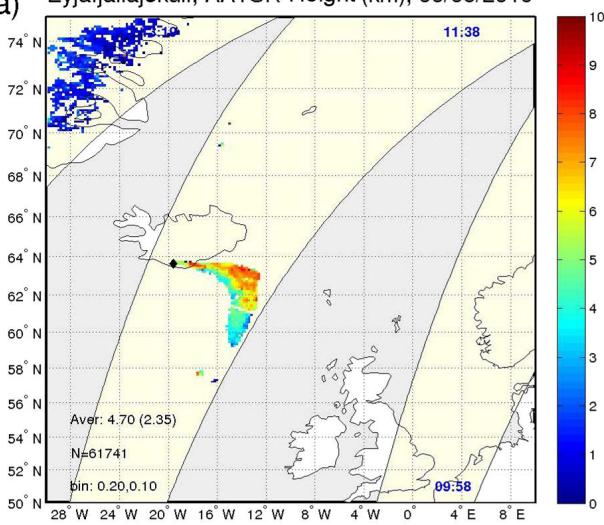

C) Eyjafjallajökull, AATSR Height $(\mathrm{km}), 14 / 05 / 2010$

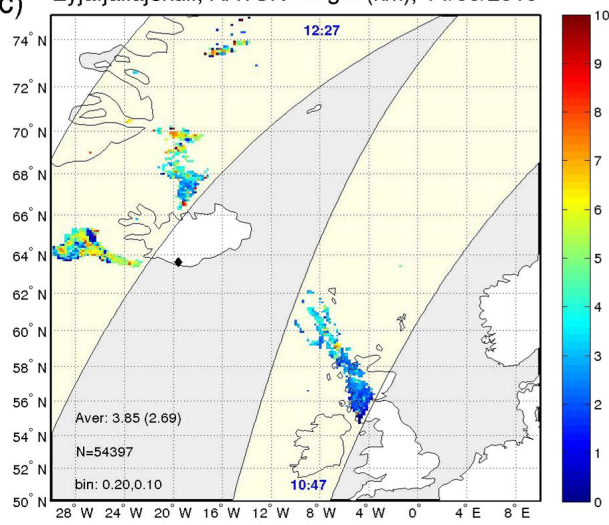

b) Eyjafjallajökull, AATSR Height $(\mathrm{km}), 13 / 05 / 2010$

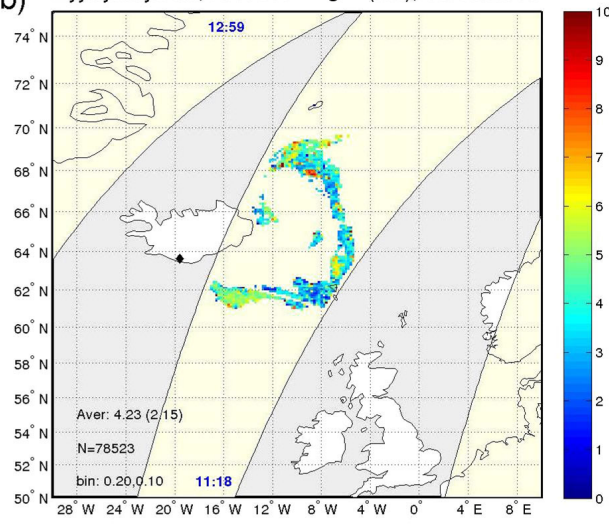

d) Eyjafjallajökull, AATSR Height (km), 15/05/2010

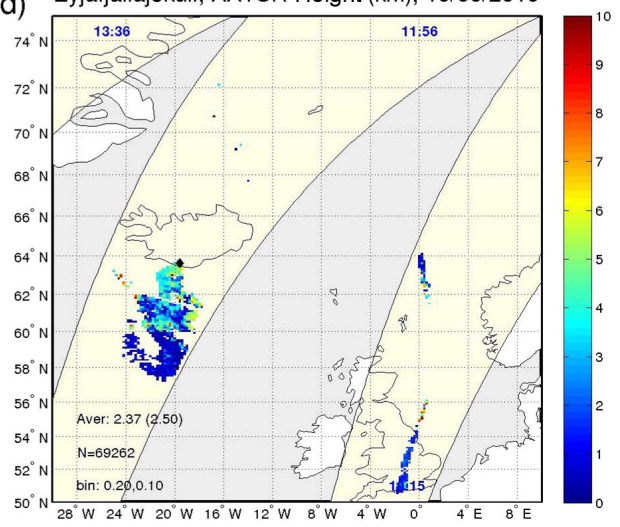

Figure 14. Single-pixel height for selected plumes on 4 days in May 2010. The yellow shaded areas show the AATSR swath, with the blue numbers giving the UTC time of the orbit. The color-coded pixels give the ACM height estimate (km a.s.l.). The text inserts in the lower left show the average height (standard deviation) and the number of pixels $N$ in each image.

the detection with the $0 \mathrm{~K}$ threshold. In the third phase of the eruption, we observe several large ash plumes and clouds in all directions around Iceland. In Fig. 14 we show the height estimate for 4 days during the latter part of the eruption. The figure also illustrates the typical AATSR swaths near Iceland; the AATSR revisit time is approximately 3 days, and even large plumes may be missed in the gaps between the orbits.

Using the $\mathrm{BTD}<0 \mathrm{~K}$ threshold, we have searched for daytime ash plumes in the period from 15 April to 18 May 2010, in an area between $40^{\circ} \mathrm{W}, 35^{\circ} \mathrm{E}$ and $40^{\circ} \mathrm{N}, 80^{\circ} \mathrm{N}$. Ash was detected on 25 AATSR orbits for 17 different days. In nighttime retrievals, 18 additional ash-affected orbits were found, on 15 different days. Days where the $0 \mathrm{~K}$ threshold showed only a limited number of isolated ash-flagged pixels were interpreted as false alerts and removed from the analysis. Although some clouds detected by the $0 \mathrm{~K}$ threshold may be false alerts, like the low-level cloud over Greenland on 6 May seen in Fig. 14a, all ash-flagged pixels are included in the analysis for the days considered for consistency.
In Table 4 we show statistics for the full eruption period for daytime orbits. The nighttime retrievals differ, for example, in the cloud screening, and they are not included in this analysis. For each day with data we list the number of ashflagged pixels $(N)$, the number of pixels after filtering $\left(N_{\mathrm{bav}}\right)$, the fraction of the filtered (best average height) pixels from the total (bav frac.), the fraction of cloud-flagged pixels (cld frac.), the fraction of pixels where the forward view is obscured (shd frac.), and the fraction of pixels where the forward view is obscured (shd frac.). Four daily average height values ( $\mathrm{km}$ a.s.l.) are also given: the daily average of filteredpixel heights (BAV) and the average single-pixel heights with the largest $\mathrm{CW}(\mathrm{SPH})$, medium size $\mathrm{CW}(\mathrm{MwH})$ and small $\mathrm{CW}$ (SwH). In Fig. 15 we show a time series of the daily average plume top heights and number of ash-flagged pixels. Typically, the smaller correlation window gives larger average heights, with more variation. The average BAV heights are lower or higher than the SPHs, depending on the case. On average, the filtering removes more than $80 \%$ of the pixels, mostly because of cloud screening. It is evident that the use of systematic thresholds for all cases leads to a large fraction 

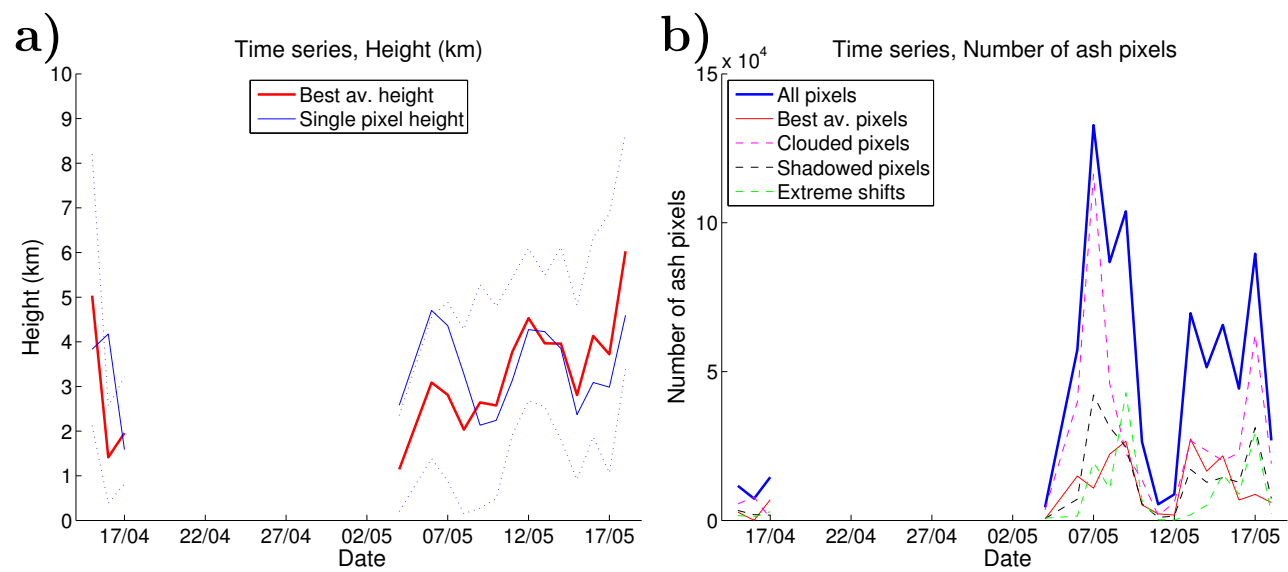

Figure 15. Time series of daily average heights and number of ash pixels. The blue lines give the average values using all pixels (SPH), and the red lines give average values using the filtered pixels only (BAV). The dotted blue lines on the left show the error bars (standard deviation). On the right we also show the number of pixels flagged as clouded or shadowed and also the number of pixels with an extreme (maximum or zero) along-track pixel shift.

Table 4. Daily average heights (standard deviations) for the Eyjafjallajökull eruption and mask fractions for daytime orbits. $N$ is the number of pixels with a valid height estimate, and bav frac. gives the fraction of filtered (best-average-height) pixels. The other fractions give the portion of pixels flagged by the cloud and shadow masks. In addition to the best average heights (BAV) and single-pixel heights (SPH) calculated with the largest correlation window size (CWS $11 \times 11)$, we show the single-pixel height calculated simultaneously with two smaller correlation window sizes; the medium window height $(\mathrm{MwH}, 9 \times 9)$ and the small window height $(\mathrm{SwH}, 7 \times 7)$. Heights are given in kilometers a.s.1.

\begin{tabular}{ccccccccc}
\hline Date & $N$ & Bav frac. & Cld frac. & Shd frac. & BAV & SPH & MwH & SwH \\
\hline 15 Apr & 11641 & $24.0 \%$ & $43.3 \%$ & $28.2 \%$ & $5.03(3.1)$ & $3.84(3.5)$ & $4.08(3.6)$ & $4.52(3.8)$ \\
$16 \mathrm{Apr}$ & 7333 & $0.9 \%$ & $97.4 \%$ & $26.2 \%$ & $1.41(1.1)$ & $4.17(3.9)$ & $4.48(4.0)$ & $4.93(4.1)$ \\
$17 \mathrm{Apr}$ & 14529 & $48.0 \%$ & $4.9 \%$ & $12.1 \%$ & $1.96(1.0)$ & $1.59(1.6)$ & $1.84(2.1)$ & $2.47(2.9)$ \\
4 May & 4431 & $10.5 \%$ & $65.1 \%$ & $12.6 \%$ & $1.14(0.3)$ & $2.58(3.2)$ & $2.87(3.6)$ & $3.44(3.9)$ \\
6 May & 57360 & $26.0 \%$ & $64.4 \%$ & $11.7 \%$ & $3.09(1.5)$ & $4.70(2.3)$ & $4.72(2.4)$ & $4.86(2.7)$ \\
7 May & 132809 & $8.2 \%$ & $83.1 \%$ & $30.8 \%$ & $2.81(1.9)$ & $4.36(3.4)$ & $4.57(3.5)$ & $4.87(3.7)$ \\
8 May & 86780 & $25.7 \%$ & $46.9 \%$ & $35.1 \%$ & $2.03(1.9)$ & $3.28(3.3)$ & $3.64(3.6)$ & $4.17(3.9)$ \\
9 May & 103825 & $25.6 \%$ & $19.0 \%$ & $23.7 \%$ & $2.64(2.4)$ & $2.13(3.0)$ & $2.50(3.3)$ & $3.11(3.6)$ \\
10 May & 26400 & $19.7 \%$ & $47.0 \%$ & $21.1 \%$ & $2.58(2.0)$ & $2.24(2.9)$ & $2.65(3.2)$ & $3.26(3.5)$ \\
11 May & 5418 & $40.8 \%$ & $27.6 \%$ & $18.7 \%$ & $3.78(1.7)$ & $3.14(2.1)$ & $3.41(2.4)$ & $3.80(2.9)$ \\
12 May & 8801 & $20.4 \%$ & $69.2 \%$ & $16.6 \%$ & $4.53(1.6)$ & $4.28(1.9)$ & $4.37(2.1)$ & $4.56(2.4)$ \\
13 May & 69639 & $39.3 \%$ & $37.7 \%$ & $23.8 \%$ & $3.97(1.4)$ & $4.23(2.2)$ & $4.42(2.5)$ & $4.77(2.9)$ \\
14 May & 51443 & $32.2 \%$ & $42.7 \%$ & $24.0 \%$ & $3.96(2.2)$ & $3.85(2.7)$ & $4.06(2.9)$ & $4.44(3.2)$ \\
15 May & 65697 & $33.0 \%$ & $28.5 \%$ & $21.5 \%$ & $2.81(1.9)$ & $2.37(2.5)$ & $2.69(2.8)$ & $3.23(3.2)$ \\
16 May & 44271 & $15.5 \%$ & $45.7 \%$ & $26.4 \%$ & $4.13(2.1)$ & $3.09(3.1)$ & $3.38(3.2)$ & $3.88(3.4)$ \\
17 May & 89623 & $9.8 \%$ & $66.8 \%$ & $34.6 \%$ & $3.72(2.8)$ & $2.99(3.6)$ & $3.48(3.8)$ & $4.13(4.0)$ \\
18 May & 26877 & $22.5 \%$ & $60.4 \%$ & $26.1 \%$ & $6.03(2.6)$ & $4.59(3.3)$ & $4.76(3.5)$ & $5.01(3.6)$ \\
\hline Total & 806877 & $22.5 \%$ & $54.3 \%$ & $26.9 \%$ & $3.21(2.2)$ & $3.41(3.2)$ & $3.70(3.3)$ & $4.15(3.6)$ \\
\hline
\end{tabular}

of the pixels being removed, while the improvement obtained in reliability is uncertain. Instead, possible thresholds and filters should be considered case by case. More abundant, reliable reference data is needed.

As a more detailed example, we study the case of 6 May 2010 over Iceland in Fig. 16. In this case, the AATSR overpass is directly over the volcano, and a large plume extends from the volcano, first directly to the east, and then turns to the south. The wind direction is captured by the across-track wind speed estimate retrieved by ACM (Fig. 16e): positive values in the northern part of the plume indicate eastward (or southeastward) wind, while the values close to 0 in the southern part correspond to a zero acrosstrack wind component. The BTD values are smallest in the middle of the plume in this case (Fig. 16f), but this is not a general rule. 

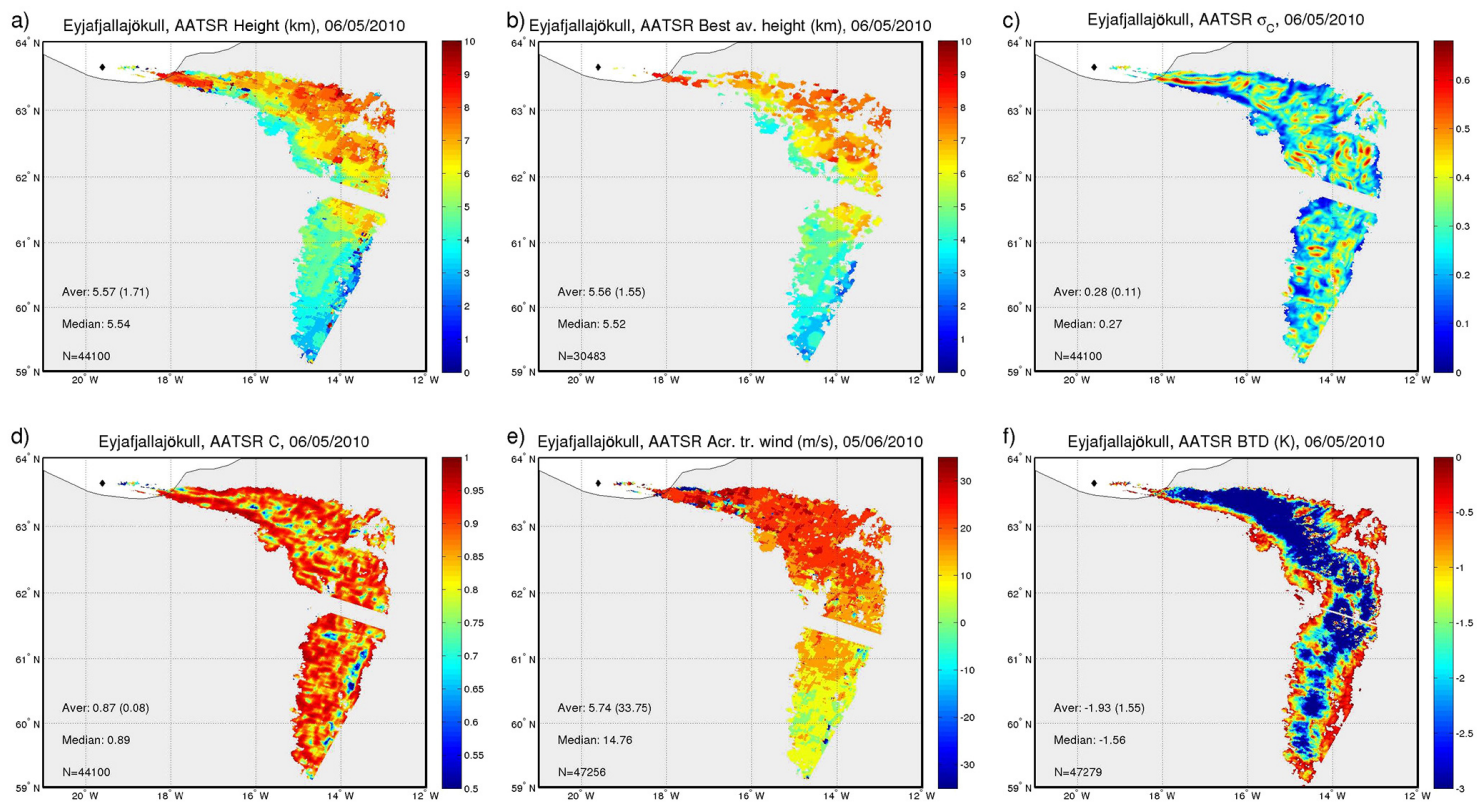

Figure 16. Example case of 6 May 2010 over Iceland. (a) Single-pixel height estimate; (b) best-average-height estimate; (c) standard deviation of $C$ within the correlation matrix; (d) the cross-correlation coefficient $C$; (e) the across-track wind speed ( $\mathrm{m} \mathrm{s}^{-1}$ ); (f) the brightness temperature difference BTD (scale limited to $-3 \mathrm{~K}$ ). The text inserts on the lower left-hand corners of the images show the average value (standard deviation) and median of each quantity and the number of pixels used. See text for details.

The height reaches $10 \mathrm{~km}$ in the eastward plume, while the southern tip of the plume is below $5 \mathrm{~km}$, with an average height of around $5.6 \mathrm{~km}$ for the whole plume (Fig. 16a). The BAV heights (Fig. 16b) are similar to the SPH values, with fewer data points remaining. The standard deviation of BAV data is slightly smaller than for the SPH data, but the average height remains nearly the same. Lower-quality pixels are removed mostly from the plume edges, but also from the central parts of the plume. For this example we have turned the cloud mask off, as it removes $65 \%$ of the plume. The gap in the height estimate data around $61.8^{\circ} \mathrm{N}$ is due to an AATSR scene edge. ACM requires margins around each scene, which results in gaps between the scenes (a technical problem to be addressed in future versions).

The correlation coefficient $C$ values range mostly from 0.5 to 0.95 , with an average of 0.87 and a 0.89 median (Fig. 16d). There is spatial variability in $C$, with a standard deviation of 0.08 . The standard deviation of $C$ within the correlation matrix $\sigma_{\mathrm{c}}$ has most of its values between 0.1 and 0.6 , with a 0.28 average, 0.27 median, and 0.11 standard deviation (within MAW). The highest $\sigma_{\mathrm{c}}$ values are typically in the central parts of the plume, and the lowest values are at the plume edges (Fig. 16c). There are no large areas where the correlation method quality parameters $C$ and $\sigma_{\mathrm{c}}$ would clearly indicate lower quality of the height estimate; hence it appears that the estimate quality cannot be easily improved by applying thresholds to these parameters. Better understanding of the use of these parameters as quality indicators would require more abundant and reliable reference data.

\section{Conclusions}

We have developed a height estimate algorithm based on cross-correlation of AATSR nadir and forward-view image pairs. The AATSR correlation method algorithm has been validated against topographic data and compared to other satellite-based instruments and in situ data and is shown to perform reasonably well. Using the algorithm and automatic ash detection based on the thermal infrared channels of AATSR, we have studied the volcanic ash plume top heights of the Eyjafjallajökull eruption in Iceland in April and May 2010.

Sensitivity of the method to various retrieval parameters is discussed in detail. An attempt is made to take into account various error sources and filter the data by quality thresholds. However, the results are inconclusive, and suitable thresholds vary from case to case. For best result, the useful quality parameter thresholds need to be manually tuned for each case.

The data are made available via the Volcanic Ash Strategic initiative Team (VAST) project web page, http://vast.nilu.no/. See also the publicly available document of AATSR plume heights (Virtanen and de Leeuw, 2013). 
Acknowledgements. This work was supported by the Centre of Excellence in Atmospheric Science, funded by the Finnish Academy of Sciences (project no. 272041), and the European Space Agency thought the project Volcanic Ash Strategic initiative Team (VAST, ESA-ESRIN Contract No. 4000105701/12/I-LG). The AATSR data were obtained from ESA. The CALIOP data were obtained through NASA Langley Research Center website (http://www-calipso.larc.nasa.gov/). The MISR data were obtained via the online archive of MISR Plume Height Project (http://misr.jpl.nasa.gov/getData/accessData/MisrMinxPlumes/). SEVIRI data were obtained through the VAST database, courtesy of F. Prata. The Keflavík weather radar data and the web camera data published by Arason et al. (2011) were obtained through the VAST database.

Edited by: O. Torres

\section{References}

AATSR 3rd Reprocessing User Note, Issue 1.0, European Space Agency: ESA AATSR internet site, available at: https: //earth.esa.int/web/guest/missions/esa-operational-eo-missions/ envisat/instruments/aatsr (last access: 14 April 2014), 2013.

Arason, P., Petersen, G. N., and Bjornsson, H.: Observations of the altitude of the volcanic plume during the eruption of Eyjafjallajökull, April-May 2010, Earth Syst. Sci. Data, 3, 9-17, doi:10.5194/essd-3-9-2011, 2011.

Clarisse, L., Prata, A. J., Lacour, J.-L., Hurtmans, D., Clerbaux, C., and Coheur, P.-F.: A correlation method for volcanic ash detection using hyperspectral infrared measurements, Geophys. Res. Lett., 37, L19806, doi:10.1029/2010GL044828, 2010.

Curier, L., de Leeuw, G., Kolmonen, P., Sundström, A.-M., Sogacheva, L., and Bennouna, Y.: Aerosol retrieval over land using the (A)ATSR dual-view algorithm, in: Satellite Aerosol Remote Sensing Over Land, edited by: Kokhanovsky, A. A. and de Leeuw, G., Springer, Berlin, 2009.

de Leeuw, G., Holzer-Popp, T., Bevan, S., Davies, W., Descloitres, J., Grainger, R. G., Griesfeller, J., Heckel, A., Kinne, S., Klüser, L., Kolmonen, P., Litvinov, P., Martynenko, D., North, P. J. R., Ovigneur, B., Pascal, N., Poulsen, C., Ramon, D., Schulz, M., Siddans, R., Sogacheva, L., Tanré, D., Thomas, G. E., Virtanen, T. H., von Hoyningen Huene, W., Vountas, M., and Pinnock, S.: Evaluation of seven European aerosol optical depth retrieval algorithms for climate analysis, Remote Sens. Environ., doi:10.1016/j.rse.2013.04.023, in press, 2013.

Ekstrand, A. L., Webley, P. W., Garay, M. J., Dehn, J., Prakash, A., Nelson, D. L., Dean, K. G., and Steensen, T.: A multi-sensor plume height analysis of the 2009 Redoubt eruption, J. Volcanology Geothermal Res. 259, 170-184, doi:10.1016/j.jvolgeores.2012.09.008, 2013.

Fisher, D., Muller, J.-P., and Yershov, V. N.: Automated stereo retrieval of smoke plume injection heights and retrieval of smoke plume masks from AATSR and their assessment with CALIPSO and MISR, IEEE T. Geosci. Remote, 52, 1249-1258, doi:10.1109/TGRS.2013.2249073, 2013.
Grainger, R. G., Peters, D. M, Thomas, G. E., Smith, A. J. A., Siddans, R., Carboni, E., and Dudhia, A., Measuring volcanic plume and ash properties from space, in: Remote Sensing of Volcanoes and Volcanic Processes: Integrating Observation and Modelling, edited by: Pyle, D. M., Mather, T. A., and Biggs, J., Geological Society, London, Special Publications, Vol. 380, doi:10.1144/SP380.7, 2013.

Gudmundsson, M. T., Thordarson, T., Höskuldsson, A., Larsen, G., Björnsson, H., Prata, A. J., Oddsson, B., Magnússon, E., Högnadóttir, T., Petersen, G. N., Hayward, C. L., Stevenson, J. A., and Jónsdóttir, I.: Ash generation and distribution from the April-May 2010 eruption of Eyjafjallajökull, Iceland, Sci. Rep., 2, 572, doi:10.1038/srep00572, 2012.

Hasler, A. F.: Stereographic observations from geosynchronous satellites: an important new tool for the atmospheric sciences, B. Am. Meteorol. Soc., 62, 194-212, 1981.

Kahn, R. A. and Limbacher, J.: Eyjafjallajökull volcano plume particle-type characterization from space-based multi-angle imaging, Atmos. Chem. Phys., 12, 9459-9477, doi:10.5194/acp12-9459-2012, 2012.

Koelemeijer, R. B. A., Stammes, P., Hovenier, J. W., and de Haan, J. D.: A fast method for retrieval of cloud parameters using oxygen A-band measurements from the Global Ozone Monitoring Instrument, J. Geophys. Res., 106, 3475-3490, 2001.

Kolmonen, P., Sundström, A.-M., Sogacheva, L., Rodriguez, E., Virtanen, T., and de Leeuw, G.: Uncertainty characterization of AOD for the AATSR dual and single view retrieval algorithms, Atmos. Meas. Tech. Discuss., 6, 4039-4075, doi:10.5194/amtd6-4039-2013, 2013.

Muller, J.-P., Mandanayake, A., Moroney, C., Davies, R., Diner, D. J., and Paradise, S.: MISR Stereoscopic Image Matchers: techniques and results, IEEE T. Geosci. Remote, 40, 15471559, doi:10.1109/TGRS.2002.801160, 2002.

Muller, J.-P., Denis, M.-A., Dundas, R. D., Mitchell, K. L., Naud, C., and Mannstein, H.: Stereo cloud-top heights and cloud fraction retrieval from ATSR-2, Int. J. Remote Sens., 28, 19211938, doi:10.1080/01431160601030975, 2007.

Naeger, A. R. and Christopher, S. A.: The identification and tracking of volcanic ash using the Meteosat Second Generation (MSG) Spinning Enhanced Visible and Infrared Imager (SEVIRI), Atmos. Meas. Tech., 7, 581-597, doi:10.5194/amt-7-581-2014, 2014.

NASA: JPL MISR plume height project webpage, available at: http: //www-misr.jpl.nasa.gov/getData/accessData/MisrMinxPlumes (last access: 14 April 2014), 2013.

Nelson, D. L., Garay, M. J., Kahn, R. A., and Dunst, B. A.: Stereoscopic Height and Wind Retrievals for Aerosol Plumes with the MISR INteractive eXplorer (MINX), Remote Sens., 5, 45934628, doi:10.3390/rs5094593, 2013.

Prata, A. J.: Radiative transfer calculations for volcanic ash clouds, Geophys. Res. Lett., 16, 1293-1296, 1989.

Prata, A. J.: Detecting and Retrieving Volcanic Ash from SEVIRI Measurements Algorithm Theoretical Basis Document v1.0, ESA/VAST, Kjeller, 67 pp., available at: http://vast.nilu.no/ project/deliverables/, 2013.

Prata, A. J. and Prata, A. T.: Eyjafjallajökull volcanic ash concentrations determined using Spin Enhanced Visible and Infrared Imager measurements, J. Geophys. Res., 117, D00U23, doi:10.1029/2011JD016800, 2012. 
Prata, A. J. and Turner, P. J.: Cloud-top height determination using ATSR data, Remote Sens. Environ., 59, 1-13, 1997.

Robles González, C.: Retrieval of Aerosol Properties Using ATSR2 Observations and Their Interpretation, Ph.D. thesis, University of Utrecht, Utrecht, the Netherlands, 2003.

Saunders, R. W. and Kriebel, K. T.: An improved method for detecting clear sky and cloudy radiances from AVHRR data, Int. J. Remote Sens., 9, 123-150, 1988.

Scollo, S., Kahn, R. A., Nelson, D. L., Coltelli, M., Diner, D. J., Garay, M. J., and Realmuto, V. J.: MISR observations of Etna volcanic plumes, J. Geophys. Res., 117, D06210, doi:10.1029/2011JD016625, 2012.

Stohl, A., Prata, A. J., Eckhardt, S., Clarisse, L., Durant, A., Henne, S., Kristiansen, N. I., Minikin, A., Schumann, U., Seibert, P., Stebel, K., Thomas, H. E., Thorsteinsson, T., Tørseth, K., and Weinzierl, B.: Determination of time- and height-resolved volcanic ash emissions and their use for quantitative ash dispersion modeling: the 2010 Eyjafjallajökull eruption, Atmos. Chem. Phys., 11, 4333-4351, doi:10.5194/acp-11-4333-2011, 2011.
Virtanen, T. H. and de Leeuw, G.: Volcanic ash plume top height estimate using AATSR algorithm theoretical basis document v1.0, ESA/VAST, Helsinki, 35 pp., available at: http://vast.nilu.no/ project/deliverables/, 2013.

Winker, D. M., Hunt, W. H., and McGill, M. J.: Initial performance assessment of CALIOP, Geophys. Res. Lett., 34, L19803, doi:10.1029/2007GL030135, 2007.

Yu, T., Rose, W. I., and Prata, A. J., Atmospheric correction for satellite-based volcanic ash mapping and retrievals using "split window" IR data from GOES and AVHRR, J. Geophys. Res., 107, 4311-4430, doi:10.1029/2001JD000706, 2002.

Zakšek, K., Hort, M., Zaletelj, J., and Langmann, B.: Monitoring volcanic ash cloud top height through simultaneous retrieval of optical data from polar orbiting and geostationary satellites, Atmos. Chem. Phys., 13, 2589-2606, doi:10.5194/acp-13-25892013, 2013. 